\title{
Photophysics, Redox Processes, and Electronic Structures of Ferrocenyl-Containing BODIPYs, aza-BODIPYs, BOPHYs, Transition-Metal Dipyrromethenes and aza-Dipyrromethenes
}

\author{
Victor N. Nemykin, ${ }^{\mathrm{a}}{ }_{1}$ Tanner S. Blesener, ${ }^{\mathrm{a}}$ and Christopher J. Ziegler ${ }^{\mathrm{b} 2}$ \\ ${ }^{a}$ Department of Chemistry, University of Manitoba, R3T 2N2 Winnipeg MB, Canada \\ bepartment of Chemistry, Akron University, Akron OH, USA \\ ${ }^{\circledR 1}$ Corresponding authorE-mail: Viktor.Nemykin@umanitoba.ca \\ ${ }^{@ 2}$ Corresponding authorE-mail: Ziegler@uakron.edu
}

General trends in the UV-Vis-NIR spectra, fluorescence and transient absorption spectroscopy, electro- and spectroelectrochemical properties, and electronic structures of ferrocenyl-containing BODIPYs, aza-BODIPYs, BOPHY, transition-metal dipyrromethanes and aza-dipyrromethenes are discussed in this mini-review.

Keywords: BODIPY, aza-BODIPY, ferrocene, dipyrromethene, aza-dipyrromethene, photophysics, redox properties.

\section{Фотофизические свойства, окислительно-восстановительные процессы и электронные структуры ферроценил-содержащих BODIPY, аза-BODIPY, BOPHY, Аипиррометеновых \\ и аза-Аипиррометеновых комплексов с переходными металлами}

\author{
В. Н. Немыкин, ${ }^{a}{ }^{a}$ T. С. Блесенер, ${ }^{a}$ K. Аж. Циглер ${ }^{\mathrm{b} 2}$ \\ ${ }^{\mathrm{a}}$ Факультет Химии, Университет Манитоба, R3Т 2N2 Виннипег МБ, Канада \\ ${ }^{\mathrm{b}}$ Факультет Химии, Университет Акрон, Акрон ОХ, США \\ (a) E-mail: Viktor.Nemykin@umanitoba.ca \\ @2E-mail:Ziegler@uakron.edu
}

\begin{abstract}
В данном миниобзоре рассмотрены основные закономерности UV-Vis-NIR спектров, поглощение флуоресценции и переходных состояний, электро- и спектроэлектрохимические свойства, а также электронные структурь ферроченил-содержащих ВОDIPY, аза-ВОDIPY, ВОРНY, дипиррометеновых и азадипиррометеновых комплексов с переходными металлами.
\end{abstract}

Ключевые слова: BODIPY, аза-BODIPY, ферроцен, дипиррометен, аза-дипиррометен, фотофизика, окислительно-восстановительные свойства. 


\section{Introduction}

Organometallic porphyrins and their analogues have attracted substantial attention in recent decades because of their potential applications in light-harvesting devices, molecular electronics, and redox-activated fluorescence imaging or bio-imaging. ${ }^{[1-5]}$ In addition, organometallic, and in particular, ferrocenyl-containing BODIPYs, azaBODIPYs, and corresponding transition metal complexes of dipyrromethenes and aza-dipyrromethenes can be thought as alternative or superior platforms for similar applications. ${ }^{[6-38]}$ Although "all organic" BODIPYs and aza-BODIPYs are known for a long time, their organometallic analogues emerged in this research field only recently. ${ }^{[39-42]}$ Synthetic pathways for preparation and some selected properties of ferrocenyl-containing BODIPYs and their analogues were recently reviewed, ${ }^{[1,2]}$ while systematic analysis of optical, photophysical, and redox properties as well as their electronic structures have not being targeted so far. In this mini-review, we will provide a systematic analysis of these properties in ferrocenyl-containing BODIPYs, aza-BODIPYs, BOPHYs, and transition-metal complexes of dypyrromethenes and aza-dipyrromethenes (Chart 1).

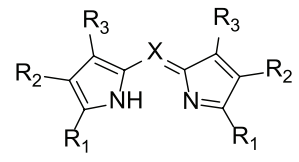

DIPY (dipyrromethene): $\mathrm{X}=\mathrm{C}-\mathrm{R}_{4}$ aza-DIPY (azadipyrromethene): $X=N$

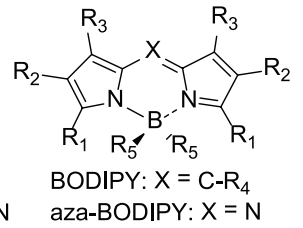

M-DIPY: $X=C-R_{4}$

M-aza-BODIPY: $X=N$

\section{Electronic Structures}

Since the optical and redox properties of the ferrocenecontaining BODIPYs, aza-BODIPYs and their analogues reflect their respective electronic structures, we will provide a brief overview on DFT-predicted electronic structures of compounds of interest in the first section. In general, the electronic structures of the ferrocene-containing BODIPYs and aza-BODIPYs and their analogues can be separated into several archetypal groups.

The first group of ferrocene-containing BODIPYs and aza-BODIPYs belongs to the systems in which ferrocene fragments are connected to the chromophore's $\pi$-system either directly or via conjugated $-\mathrm{CH}=\mathrm{CH}-\pi$-bonds (compounds 1-26). ${ }^{[6,9,10,15,16,18,22,25-27,33-35]}$ In a typical situation for this class of compounds, the DFT-predicted HOMO is dominated by ferrocene contribution with substantial (in some cases close to $50 \%$ ) contribution from the BODIPY of aza-BODIPY $\pi$-system (compounds $4, \mathbf{5}, \mathbf{7}, \mathbf{8}$, Figure 1) ${ }^{[6,22]}$ It seems that an extension of the $\pi$-system in BODIPY's core with electron-rich $\mathrm{N}, \mathrm{N}$-dimethyl- $p-\mathrm{C}_{6} \mathrm{H}_{4}-\mathrm{CH}=\mathrm{CH}-$ (compound 17) ${ }^{[16]}$ or merocyanine fragments (compounds 24 and 25) ${ }^{[35]}$ results is a situation when the DFT-predicted HOMO is predominantly localized at the BODIPY's core, with ferrocene-centered orbitals predicted just in close proximity to the HOMO (Figure 1). Electrochemical data on compound $\mathbf{1 7}$ and its non-ferrocene-containing precursor, however, indicate that the ferrocene fragment in $\mathbf{1 7}$ should be oxidized first, and this assignment was further confirmed by the spectroelectrochemical and chemical oxidation data. ${ }^{[16]}$ The most likely explanation for the discrepancy between electrochemical and DFT-predicted nature of the HOMO in $\mathbf{1 7}$ is the choice of the B3LYP exchangecorrelation functional, which is a common problem in DFT and TDDFT calculations of the electronic structures and optical properties of ferrocene-containing BODIPYs and aza-BODIPYs. Indeed, as was pointed out in refs. ${ }^{[1]}$ and ${ }^{[43]}$, pure GGA exchange-correlation functional tends to stabilize the energies of $\pi$-chromophore's core-centered $\pi$-orbitals compared to the energies of the ferrocene-centered MOs.

Chart 1.
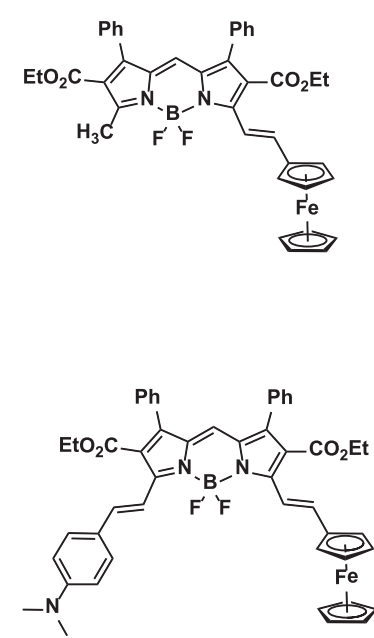

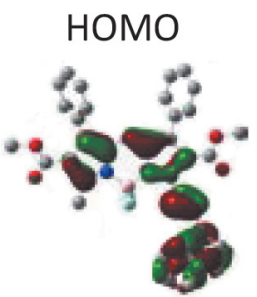

LUMO
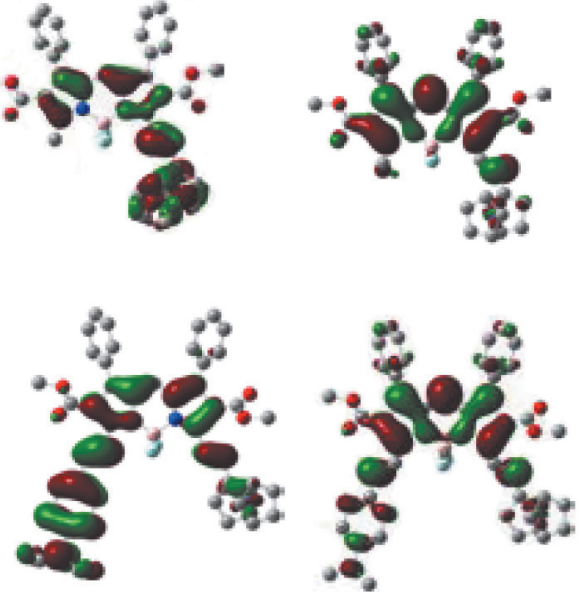

Figure 1. Typical DFT-predicted frontier orbitals for ferrocenyl-containing BODIPYs. Adapted from reference ${ }^{[16]}$. 


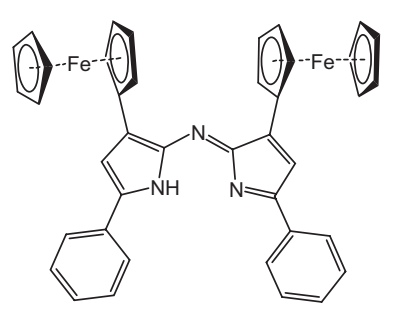

1

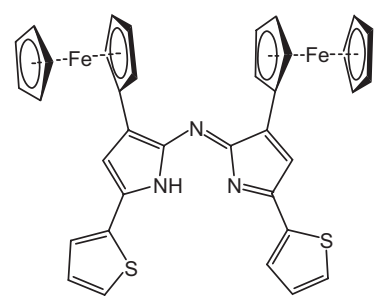

2

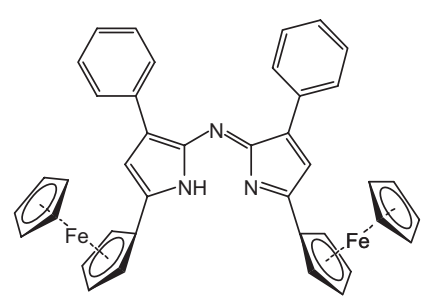

3

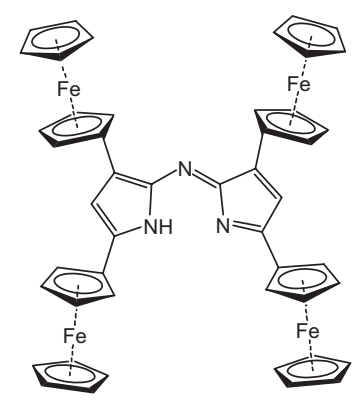

4

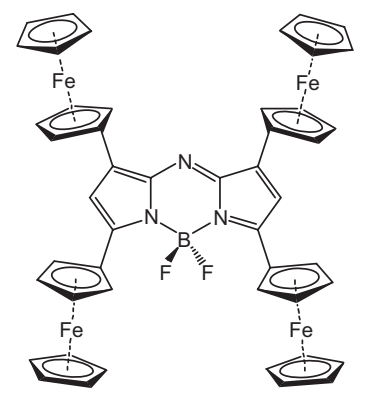

8

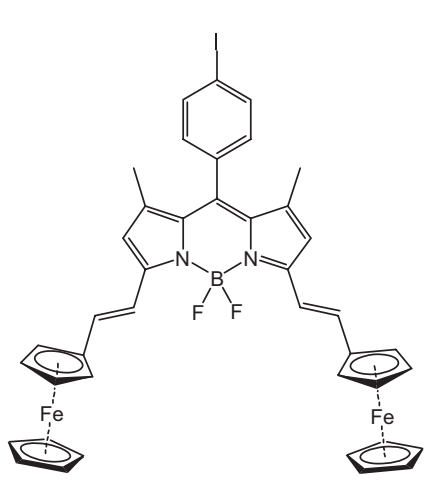

12

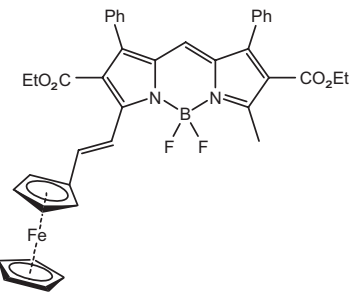

16

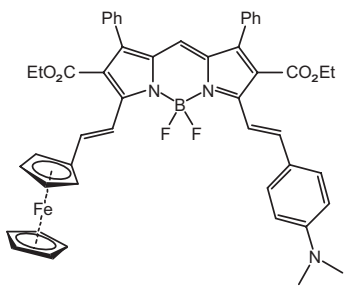

17

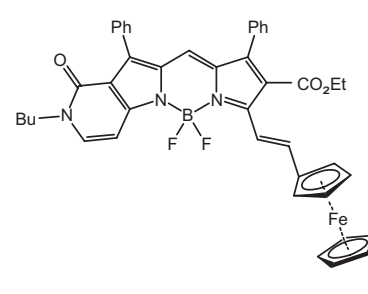

18

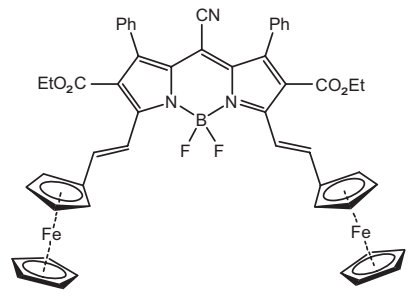

15

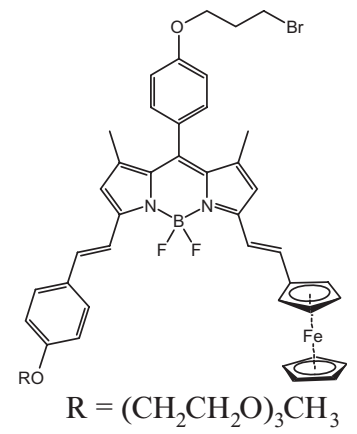

19

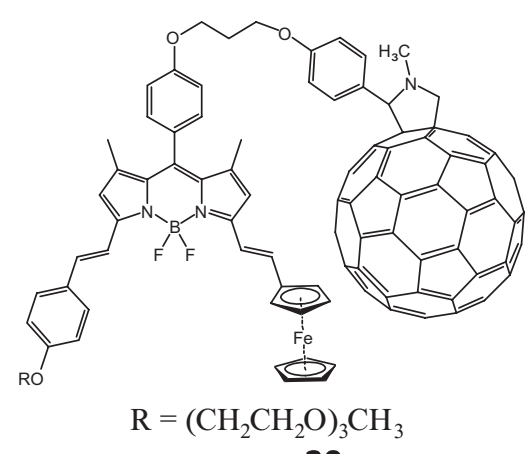

20 


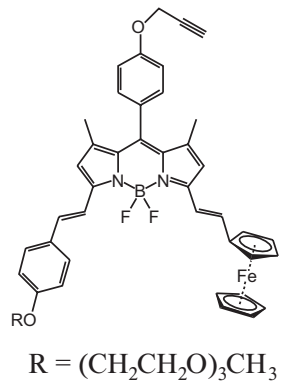

21

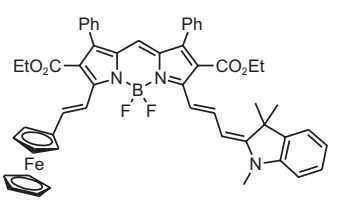

25

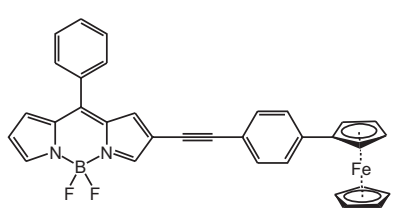

29

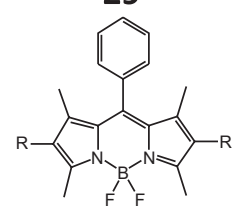

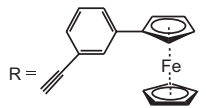

33

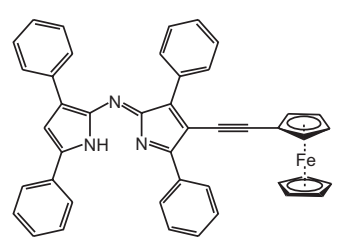

37

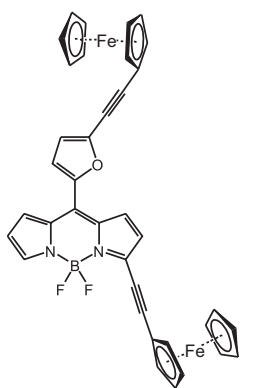

41

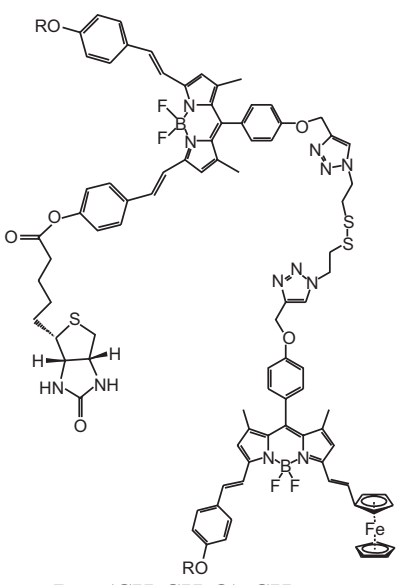

$\mathrm{R}=\left(\mathrm{CH}_{2} \mathrm{CH}_{2} \mathrm{O}\right)_{3} \mathrm{CH}_{3}$

22

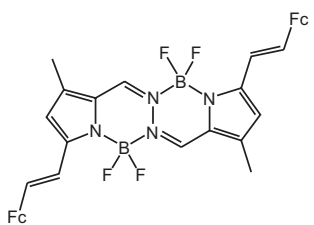

26

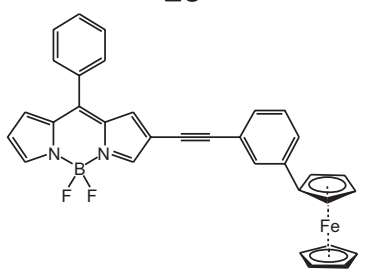

30

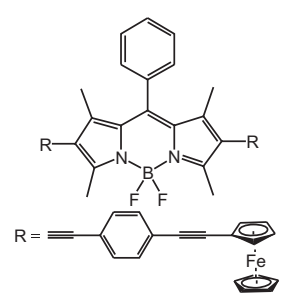

34

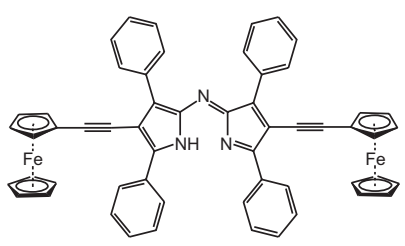

38

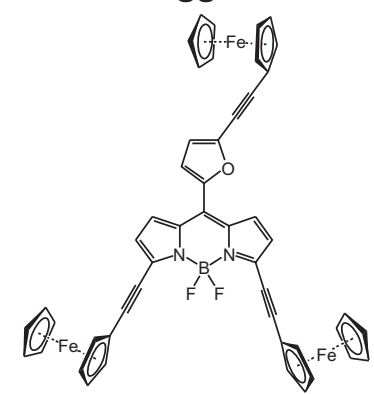

42

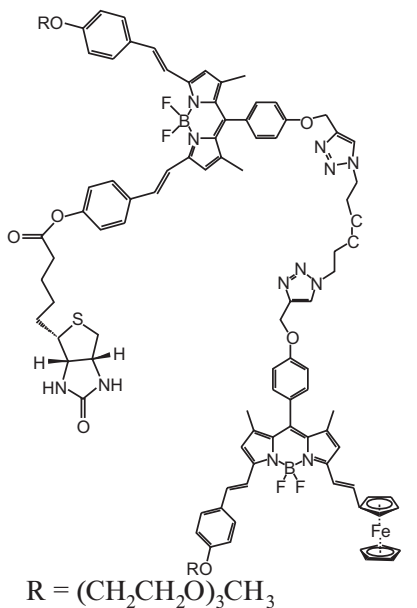

23

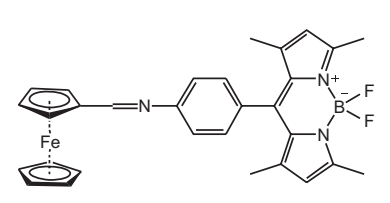

27

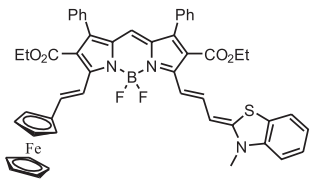

24

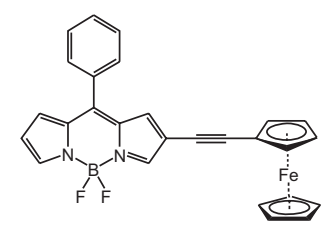

28

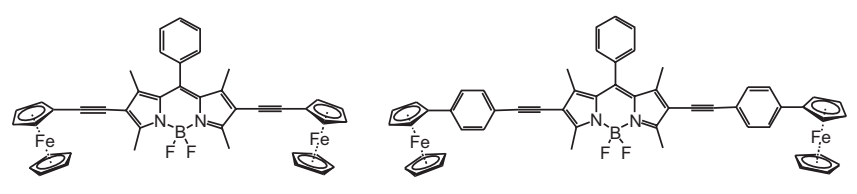

31

32

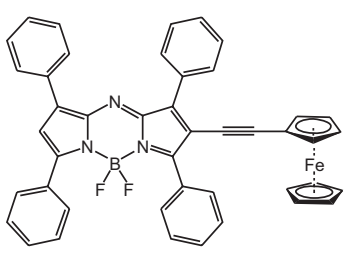

35

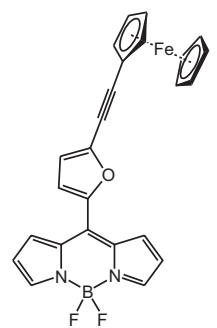

39

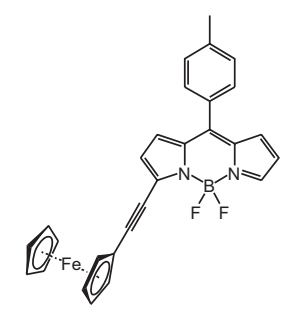

43

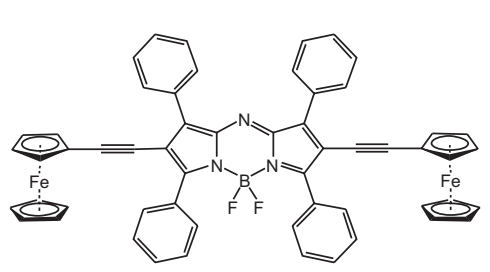

36

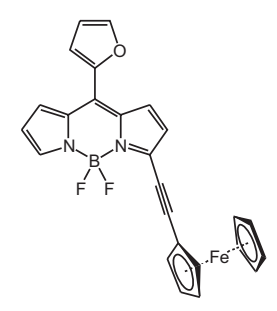

40

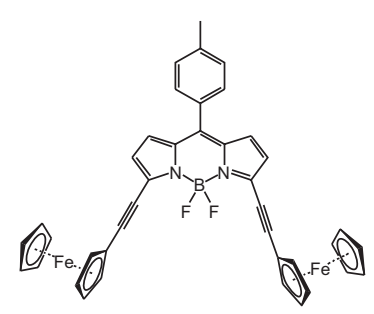

44 


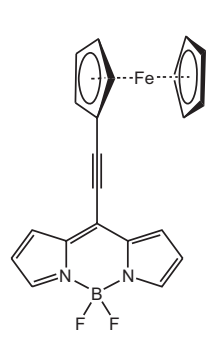

45

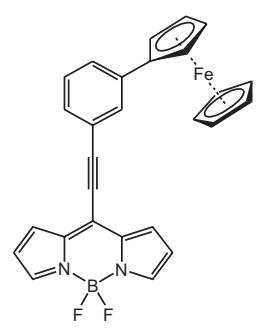

49

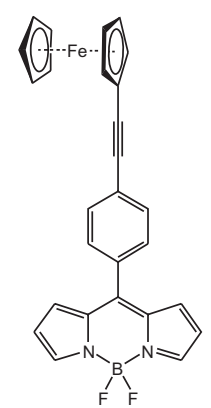

46

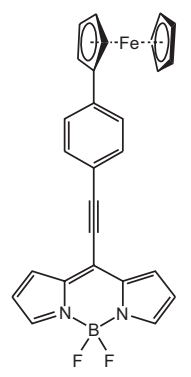

50

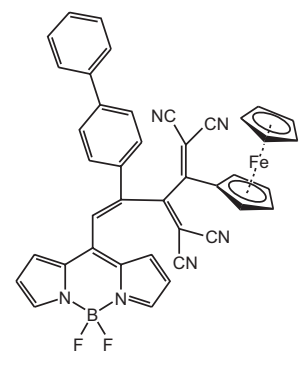

54

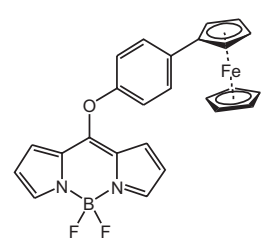

58

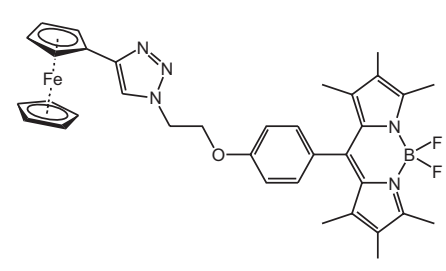

62

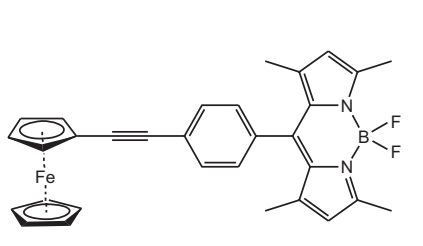

47

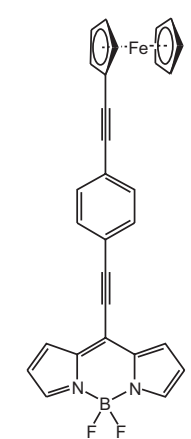

51

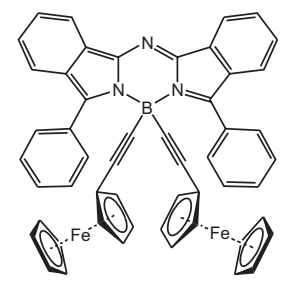

55

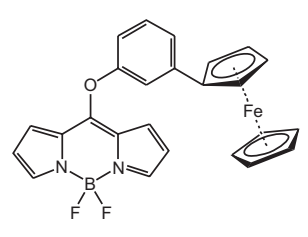

59

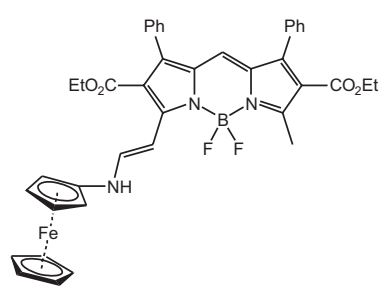

63

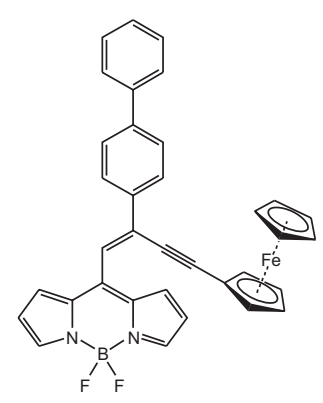

48

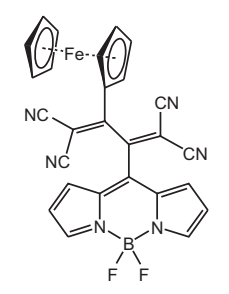

52

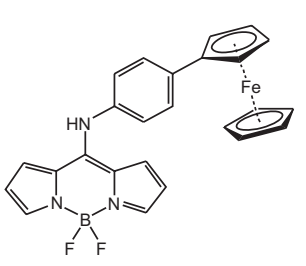

56

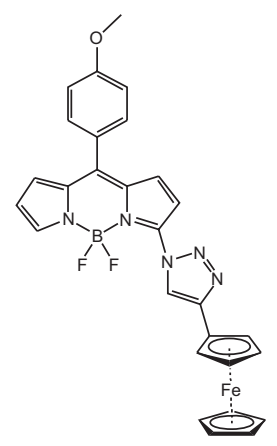

60

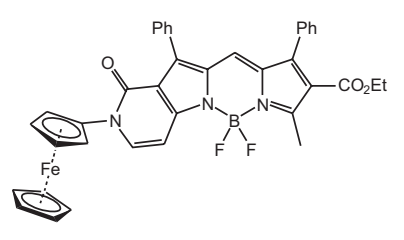

64 


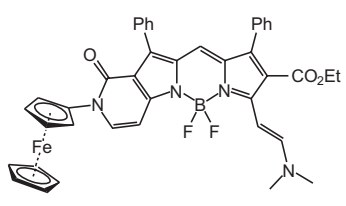

65

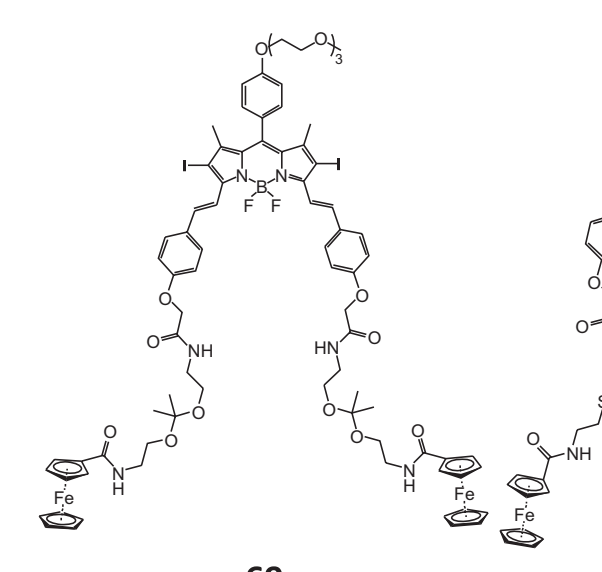

69

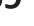

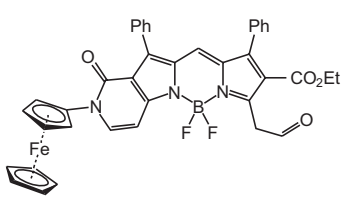

66

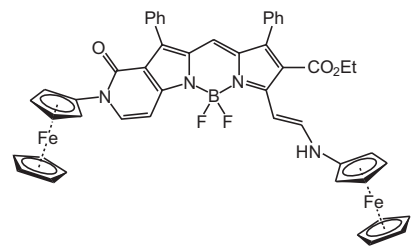

67

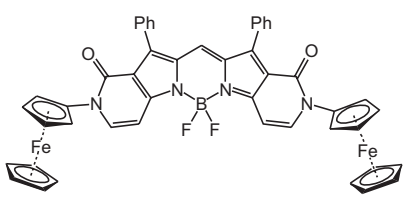

68

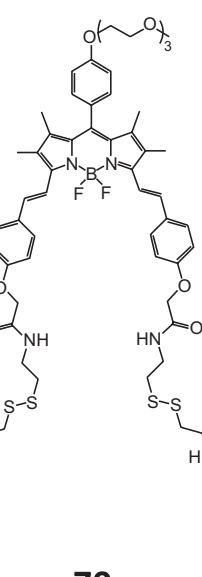

70

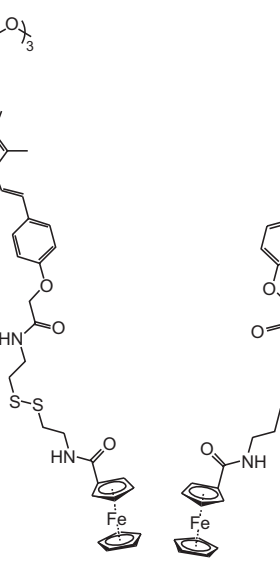

.

71

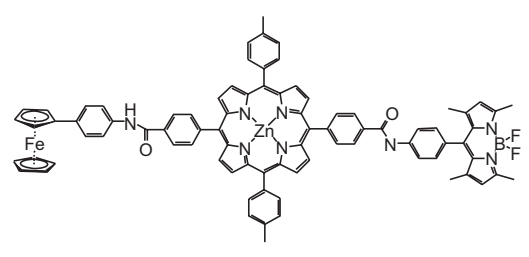

75

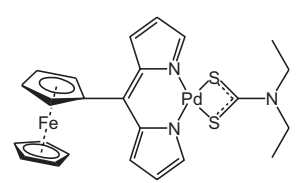

79

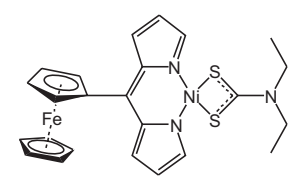

76

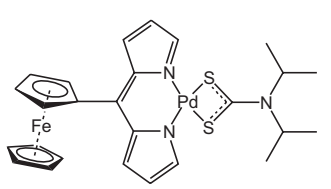

80

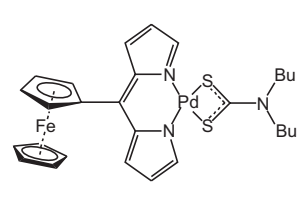

81

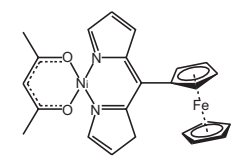

85

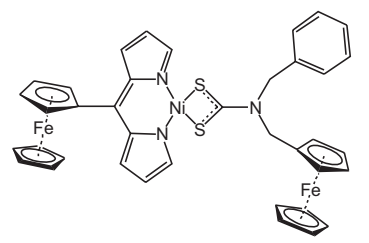

82

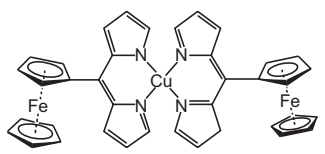

86

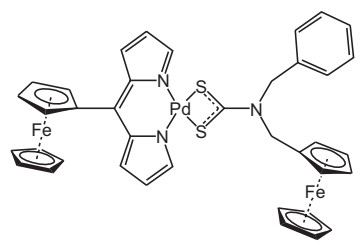

83

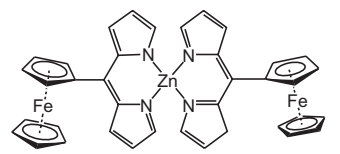

87

Chart 2. 


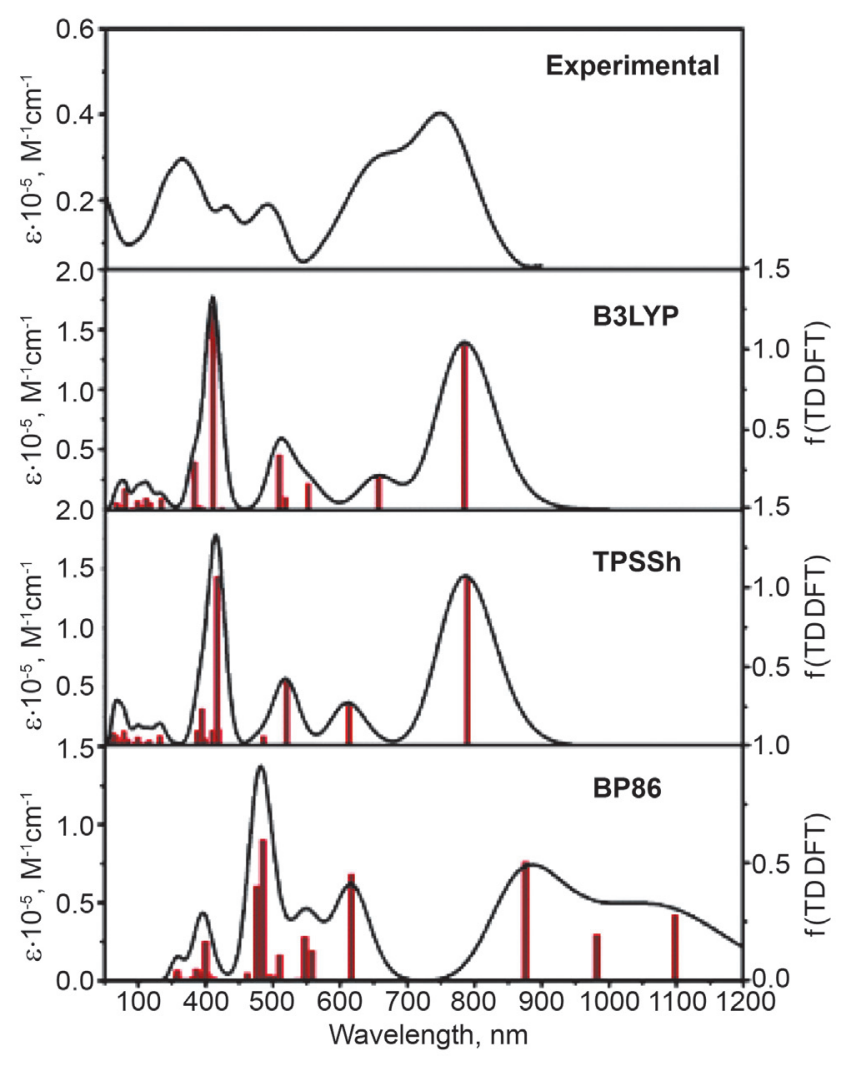

Figure 2. Comparison between experimental and TDDFTpredicted UV-Vis-NIR spectra of BODIPY 17. Reproduced with permission from the American Chemical Society. ${ }^{[16]}$

However, it seems that the pure GGA exchange-correlation functional fails (in general) to predict energies and intensities of both metal-to-ligand charge-transfer (MLCT) and $\pi-\pi^{*}$ transitions in ferrocene-containing BODIPYs and their analogues (Figure 2). ${ }^{[16,44]}$

Electrochemical data on ferrocene-merocyanine compounds 24 - 25 and their non-ferrocene precursors are indicate that the first irreversible oxidation is localized on the BODIPY's $\pi$-system and DFT calculations correlate well with experimental data (Figure 3). ${ }^{[35]}$ In the case of tetraferrocene-containing aza-BODIPY $\mathbf{8}$ and the corresponding aza-dipyrromethene 4 , the DFT-predicted
HOMO has contributions from all four ferrocene fragments with higher contribution from the ferrocene groups located at the $\alpha$-pyrrolic positions (Figure 4) ${ }^{[6]}$ In all cases, when DFT data are available, the HOMO has no electron-density at the meso-atom position (8-position of BODIPY's core) and resembles half of the " $a_{1 u}$ " (in Gouterman's four-orbital model) orbital of the porphyrin core. In contrast, the LUMO is a BODIPY or aza-BODIPY centered orbital with significant contribution from the meso-atom. A similar electronic structure was also predicted by the DFT calculations for diferrocene BOPHY system 26 (Figure 5). ${ }^{[18]}$

In the second group of compounds, the ferrocene fragments are connected to the BODIPY core either via - $\mathrm{C} \equiv \mathrm{C}$ - or/and phenyl linking groups..$^{[8,13,24,26,29,30,33]}$ When a ferrocene fragment is connected to a BODIPY core via a $-\mathrm{C} \equiv \mathrm{C}-\mathrm{C}_{6} \mathrm{H}_{4}-$ fragment, the DFT-predicted HOMO is dominated by the organometallic group (compounds 46-51), while DFT predicts that the HOMO in BODIPY 45 with $-\mathrm{C} \equiv \mathrm{C}-\mathrm{Fc}$ group connected to the BODIPY core at the mesoposition should be BODIPY-centered, which contradicts electrochemical data. ${ }^{[13,24]}$ Even in the case when only one ferrocene group is connected via $-\mathrm{C} \equiv \mathrm{C}$ - linking group at the meso-carbon atom, the nature of the DFT-predicted HOMO can be controversial. For instance, the B3LYP-predicted HOMOs in compound $\mathbf{4 6}$ and its furyl analogue 39 are clearly ferrocene-centered, ${ }^{[29]}$ while the B3LYP-predicted HOMO in tetramethyl analogue 47 was predicted to be BODIPYcentered. ${ }^{[32]}$ The first oxidation potential in both compounds, however, is close to each other and localized at the ferrocene fragment. In a very recent publication, Misra and co-workers discussed the electronic structures of ferrocene-containing BODIPYs 52-54 in which strong electron-withdrawing fragments are part of the conjugated linking groups. ${ }^{[13]}$ In these cases, the B3LYP-predicted HOMOs are BODIPYcentered, although a number of ferrocene-centered MOs was predicted in close energy proximity. Finally, in the case of compound $\mathbf{3 6}$ with two $-\mathrm{C} \equiv \mathrm{C}-\mathrm{Fc}$ groups connected to the aza-BODIPY core at the $\beta$-pyrrolic $(1,7-)$ position, the B3LYP-predicted HOMO is quite delocalized between organometallic fragments and the aza-BODIPY core. ${ }^{[8]}$ Again, for all compounds that are typical for this second group, the DFT-predicted HOMO has no electron density at the meso-position, while a large contribution from the mesoatom was observed in the LUMO.

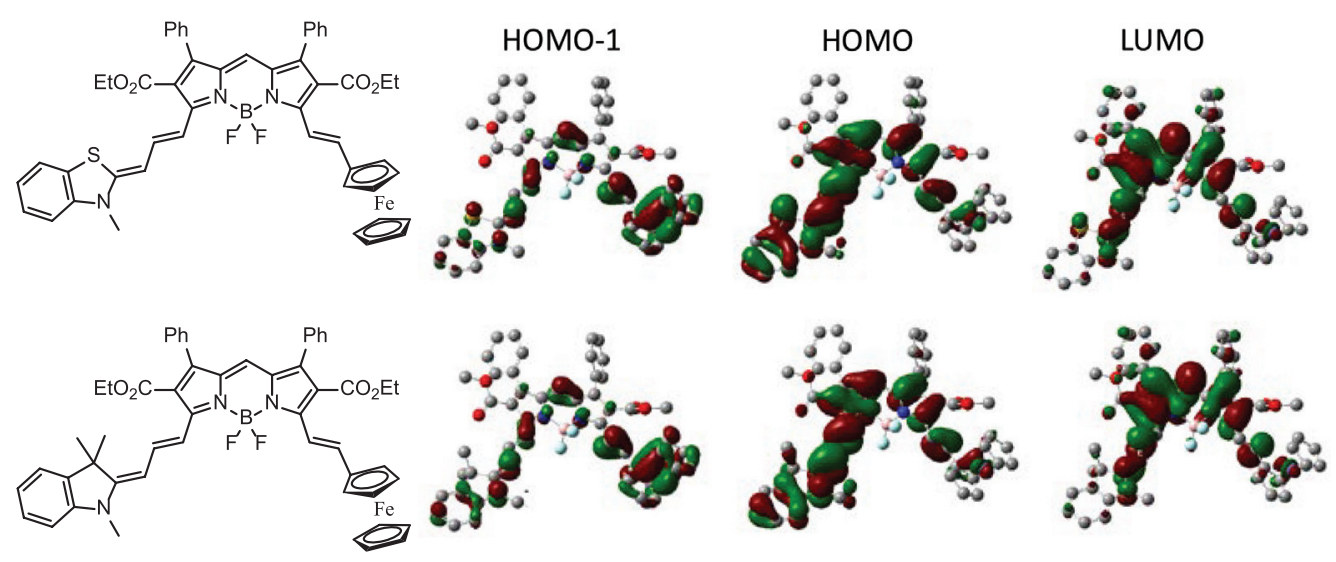

Figure 3. DFT-predicted frontier MOs for BODIPYs 24 and 25. ${ }^{[35]}$ 

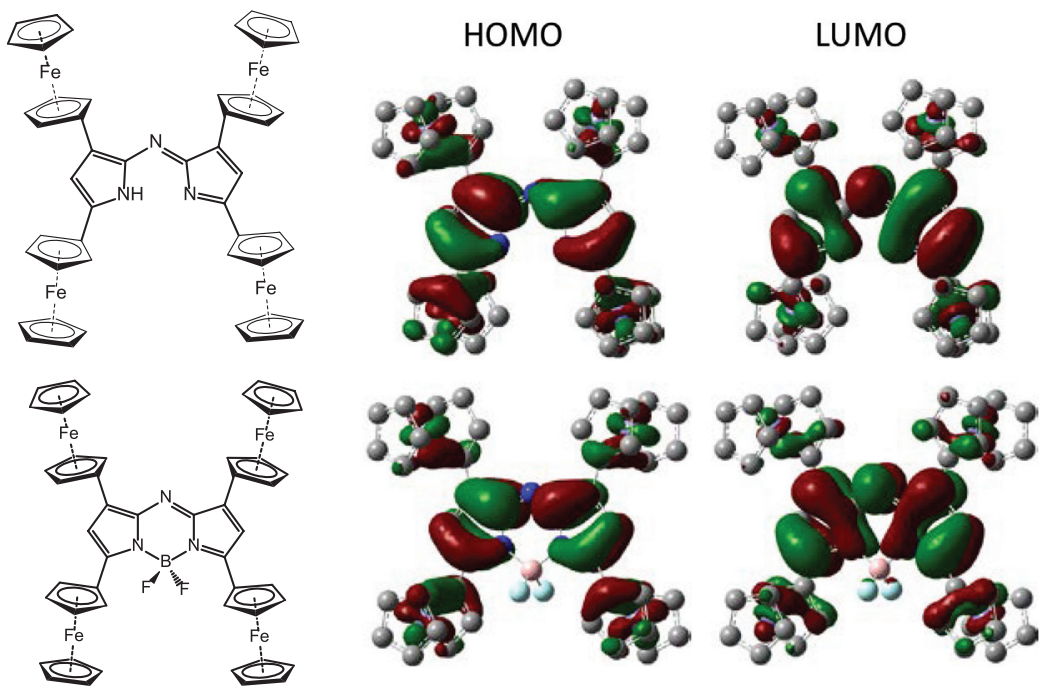

Figure 4. DFT-predicted frontier MOs for $\mathbf{4}$ and $\mathbf{8}$. Modified from reference ${ }^{[6]}$.
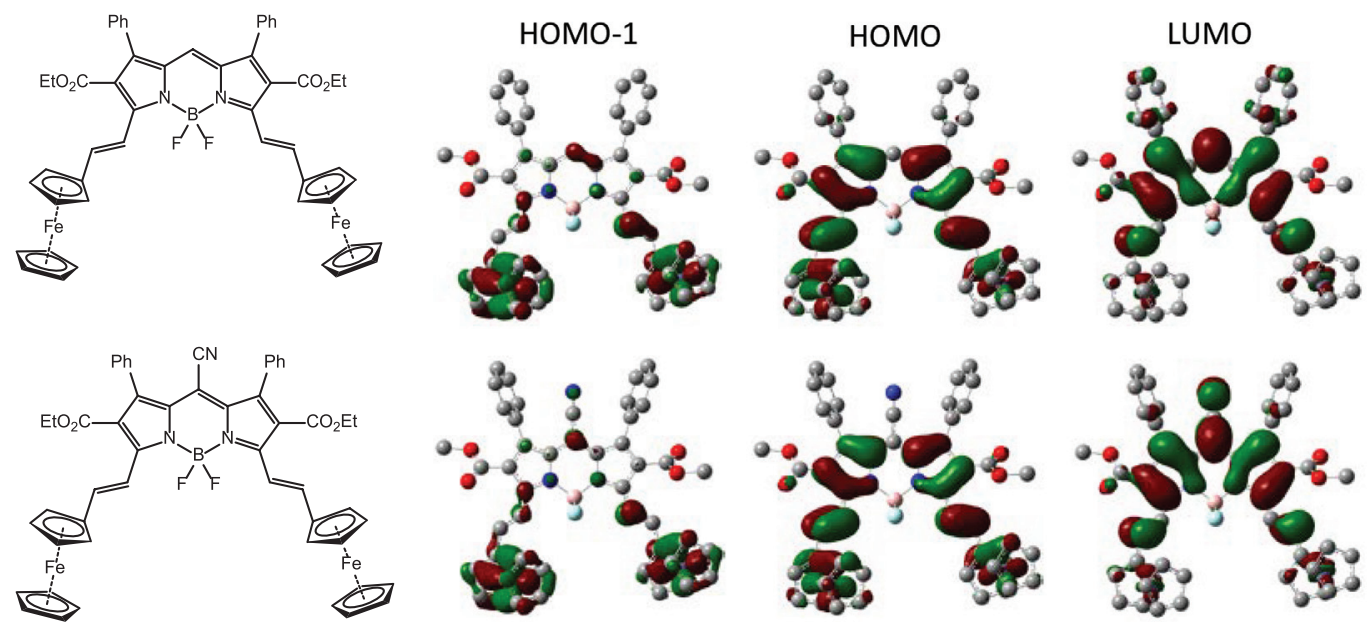

Figure 5. DFT-predicted frontier MOs for BODIPYs 13 and 15. Adapted from reference ${ }^{[9]}$.

In the third group of the ferrocene-containing BODIPYs and aza-BODIPYs, the ferrocene fragments are connected to the chromophore's $\pi$-system either at the boron hub or via a fragment, which has an $s p^{3}$ hybridized heteroatom (compounds 55-75). ${ }^{[7,12,14,17,19-21,23]}$ In these cases, the ferrocene fragments are electronically decoupled from the BODIPY's or aza-BODIPY's $\pi$-system, and to a large extent have independent behavior. For all cases, the DFT-predicted HOMOs are entirely or almost entirely localized at the ferrocene fragments, while the LUMOs are pure BODIPY's or aza-BODIPY's centered orbitals. The one exception in this group is compound $\mathbf{6 8}$ in which the DFT-predicted HOMO is highly delocalized between organometallic fragments and BODIPY core. ${ }^{[7]}$

The electronic structures of the transition-metal dipyrromethenes 76-87 were not investigated by DFT calculations. ${ }^{[36-38]}$ Nevertheless, based on available electrochemical data on some of these compounds, one might expect that the HOMO in these systems should be ferrocene-centered, which is similar to the compounds described above.
Overall, the ferrocene-containing BODIPYs and their analogues have several common features in terms of their electronic structures. In particular, predominantly ferrocene-centered orbitals were always predicted by DFT calculations for the HOMO energy region. In many cases, the DFT-predicted HOMOs have ferrocene character or ferrocene-centered orbitals were found in close energy proximity to the HOMO. In all known cases of ferrocenecontaining BODIPYs and their analogues, the LUMO has no contribution from the ferrocene fragment(s). In the most of case, DFT and TDDFT calculations using standard hybrid (20\% of Hartree-Fock exchange) B3LYP exchange-correlation functional coupled with doubleor triple- $\zeta$ quality basis sets provide a good agreement between theoretical and experimental data. ${ }^{[6-9,11,13,16,19,21,23-}$ $25,29,32,35]$ In several cases of the ferrocenyl-containing azaBODIPYs and BOPHY, however, it was shown that use of the hybrid TPSSh (10\% of Hartree-Fock exchange) results in better correlation between theoretical and experimental data. ${ }^{[17,18,22]}$ 
The electronic structures of oxidized ferrocene-containing BODIPYs and aza-BODIPYs species were probed only in two cases, which is not surprising taking into consideration higher computational cost and potential electron density distribution problems. In the case of monoferrocenyl BODIPY $[46]^{+},{ }^{[29]}$ the spin density was found as expected at the ferrocene fragment, with a negligible contribution from the BODIPY core. In the case of one-electron oxidized tetraferrocenyl-containing aza-BODIPY $[\mathbf{8}]^{+}$and the corresponding azadipyrromethene $[4]^{+}$, the DFT-predicted spin density is localized on one of the ferrocene groups directly connected to the $\alpha$-pyrrolic position, confirming spectroelectrochemical and chemical oxidation assignments (Figure 6). ${ }^{[6]}$
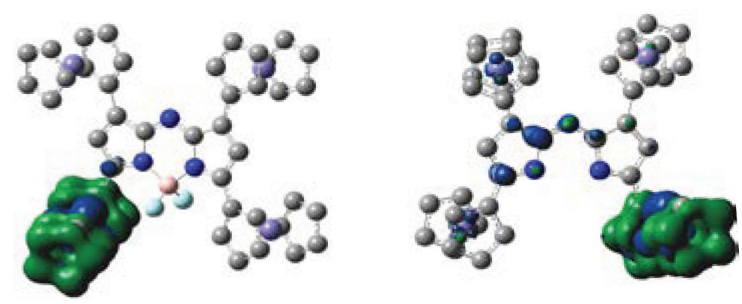

Figure 6. DFT-predicted total spin densities in $\mathbf{8}$ (left) and $\mathbf{4}$ (right). Reproduced with permission from the American Chemical Society. ${ }^{[6]}$

\section{Optical Properties}

BODIPYs and their analogues are well-known chromophores with intense absorption bands observed in the visible and sometime near-infra-red (NIR) regions. ${ }^{[39-42]}$ The most intense, low-energy transition is these chromophores is typically dominated by the $\mathrm{HOMO} \rightarrow$ LUMO single-electron excitation and has clear $\pi-\pi^{*}$ character. The energies of the most intense low-energy bands in BODIPYs and their analogues can be easily tuned by electron-donating or electronwithdrawing substituents located at $\alpha$ - or $\beta$-positions of the BODIPY core as it correlatesto a large extent the HOMOLUMO energy gap. ${ }^{[39-42]}$ As discussed above, addition of the ferrocenyl substituents onto the BODIPY core introduces ferrocene-centered molecular orbitals (MOs) to the HOMOLUMO energy region. Depending on the nature of the organic $\pi$-system, the energies of such ferrocene-centered MOs can be higher or lower than the BODIPY-centered occupied $\pi$-orbitals. Independently, however, the presence of the ferrocene-centered MOs in the HOMO energy region opens the potential for observation of low-energy metal-toligand charge-transfer (MLCT) bands in ferrocenyl-containing BODIPYs and their analogues. The intensities of these low-energy MLCT bands would depend on the location of the ferrocene fragments, the nature of linking group, and ability to borrow intensity from the chromophore-centered $\pi-\pi^{*}$ transitions (i.e. degree of delocalization between ferrocene centered fragments and chromophore core, Table 1).

Indeed, in cases, when ferrocene fragments are completely decoupled from the chromophore's $\pi$-system (compounds 60-62, 6-75) ${ }^{[12,14,19,20,23]}$ no MLCT bands are observed in the low-energy region. BODIPYs with a ferrocene fragment connected to the meso-carbon via a heteroatom linker are also have low-energy MLCT bands of very low intensity.

These is some controversy observed in case of the UV-Vis spectra of meso-ferrocenyl BODIPYs. For instance, Ravikanth and co-workers reported a low-intensity broad MLCT band at $656 \mathrm{~nm}$ in meso-ferrocenyl (8-ferrocenyl) BODIPY 9, ${ }^{[33]}$ while no MLCT band was observed by Ma and co-workers in the UV-Vis spectrum of the 8-ferrocenyl-1,3,5,7-tetramethyl BODIPY analogue. ${ }^{[28]} 2$-Ferrocenyl8-phenyl BODIPY 10 has clearly observable broad MLCT transition in the $\sim 680 \mathrm{~nm}$ region ${ }^{[26]}$ and similar results were reported for 1,7-diferrocenyl-3,5-dithienyl aza-BODIPY 6 and the corresponding azadipyrromethene $2 .^{[10]}$ In case of the 1,7-diferrocenyl-3,5-diphenyl aza-BODIPY $\mathbf{5}$ and the related azadipyrromethene $\mathbf{1}$, the MLCT band overlaps with the more intense chromophore-centered $\pi-\pi^{*}$ transition. ${ }^{[10]}$ 3,5-Diferrocenyl-1,7-diphenyl aza-BODIPY 7 and the corresponding azadipyrromethene $\mathbf{3}$ have very intense MLCT bands observed at 850 and $673 \mathrm{~nm}$, respectively (Figure 7). ${ }^{[22]}$ Finally, UV-Vis-NIR spectra of the tetraferrocenyl-containing systems $\mathbf{8}$ and $\mathbf{4}$ are dominated by the low-energy MLCT transitions (Figure 7). ${ }^{[6]}$

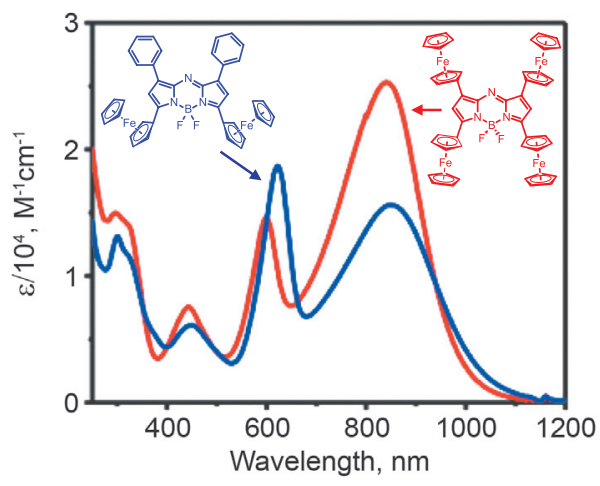

Figure 7. UV-Vis-NIR spectra of ferrocenyl-containing aza-BODIPYs with direct ferrocene-aza-BODIPY bonds. ${ }^{[6,22]}$

Ferrocenyl-containing BODIPYs $\mathbf{1 1}^{[32]}$ and $46^{[33]}$ with ferrocene fragments linked to the BODIPY core via phenyl groups have UV-vis spectra indistinguishable from the parent BODIPYs. In contrary, furyl-containing BODIPY $3^{[29]}$ and acethyleneferrocene-containing BODIPY 45 ${ }^{[13,24]}$ have clear MLCT bands in the low-energy region of their absorption spectra. Similar MLCT bands were observed in the case of acetyleneferrocene BODIPYs 43 and $44^{[33]}$ with ferrocene fragments attached to the BODIPY core via 3- or 3,5-positions. The intensities of the MLCT bands are significantly reduced in BODIPYs in which an additional phenyl linking group is present. ${ }^{[8,12,13]}$

BODIPYs with vinylferrocene fragments connected to the BODIPY core at 3- or 3,5-positions have intense lowenergy MLCT bands. These bands dominate the UV-VisNIR region in case of the diferrocenyl-containing systems 12-15 (Figure 8), ${ }^{[9,16,25,34]}$ while clear overlap between MLCT transitions and $\pi-\pi^{*}$ bands are observed in asymmetric BODIPYs $\mathbf{1 7}^{[16]}$ and 19-20 ${ }^{[27]}$ with strong electron-donating $N, N$-dimethylaminophenyl- or phenoxy-substituents. Diferrocenyl-containing BOPHY chromophore $\mathbf{2 6}^{[18]}$ has a very 
Ferrocenyl-Containing BODIPYs, aza-BODIPYs, BOPHYs, Transition-Metal Dipyrromethenes and aza-Dipyrromethenes

Table 1. UV-Vis-NIR spectra and photophysics of ferrocenyl-containing BODIPYs and their analogues.

\begin{tabular}{|c|c|c|c|c|c|c|}
\hline Compounds & Solvent & $\lambda_{\text {abs }}, \mathrm{nm}\left(\varepsilon, \mathrm{M}^{-1} \cdot \mathrm{cm}^{-1}\right)$ & $\lambda_{\mathrm{em}}, \mathrm{nm}$ & $\Phi$ & $\tau, \mathrm{ns}$ & Ref. \\
\hline 1 & DCM & $582(47000), 724(3910)$ & & & & ${ }^{[10]}$ \\
\hline 2 & DCM & $613(4720), 735(4680)$ & & & & [10] \\
\hline 3 & DCM & 313 (21000), 543 (19000), 673 (15000) & & & & [22] \\
\hline 4 & DCM & $310,535(10000), 697(18000)$ & & & & [6] \\
\hline 5 & DCM & 459 (4380), 628 (4970), $856(4380)$ & & & & [10] \\
\hline 6 & DCM & 471 (4370), 680 (5000), $824(4320)$ & & & & [10] \\
\hline 7 & DCM & $450(5000), 623(15500), 850(14000)$ & & & & [22] \\
\hline 8 & DCM & $310,599(12500), 837(25000)$ & & & & [6] \\
\hline 9 & Toluene & 509 (75857), $656(5248)$ & & & & [33] \\
\hline 10 & Toluene & $350,400,513(32300)$ & & & & [26] \\
\hline 11 & DCM & $245,280,350,498$ & & & & [32] \\
\hline 12 & DCM & $340,550,700$ & & & & [34] \\
\hline 13 & DCM & $358(17000), 575$ (18000), 750 (16000) & 645 & & 0.176 & {$[16]$} \\
\hline 14 & DCM & $342,590,739(30000)$ & & & & [25] \\
\hline 15 & DCM & $\begin{array}{c}370(30000), 420(26500), 654(48000), \\
926(27000)\end{array}$ & & & & [9] \\
\hline 16 & DCM & 369 (18000), 554 (54000), 671 (18000) & 595 & & 0.136 & {$[16]$} \\
\hline 17 & DCM & $363(29000), 650(31000), 750(40000)$ & 640 & & 0.260 & {$[16]$} \\
\hline 18 & DCM & 366 (12000), 613 (48000), 715 (22000) & 655 & & 0.260 & [16] \\
\hline 19 & $\mathrm{PhCN}$ & $370,590,660$ & & & & [27] \\
\hline 20 & $\mathrm{PhCN}$ & $370,590,660$ & 591,670 & 0.54 & 0.5 & [27] \\
\hline 21 & DMF & 360 (42657), 585 (42657), 659 (38018) & & & & {$[15]$} \\
\hline 22 & DMF & 362 (75857), 583 (72443), 638 (109647) & 648 & & & [15] \\
\hline 23 & DMF & 362 (89125), 583 (81283), 638 (125892) & 648 & & & {$[15]$} \\
\hline 24 & DCM & $370,446,818(59300)$ & & & & [35] \\
\hline 25 & DCM & $370,440,495,810(118000)$ & & & & {$[35]$} \\
\hline 26 & DCM & $343(28000), 694(32000)$ & & & & [18] \\
\hline 27 & THF & $492(29400)$ & & & & [11] \\
\hline 28 & Toluene & $350,400,523(32400)$ & 546 & 0.002 & & [26] \\
\hline 29 & Toluene & $305,350,400,543(35900)$ & 590 & 0.009 & & [26] \\
\hline 30 & Toluene & $350,400,544(35700)$ & 591 & 0.018 & & [26] \\
\hline 31 & Toluene & $405,583(15500)$ & & & & [30] \\
\hline 32 & Toluene & $340,405,590(42800)$ & & & & [30] \\
\hline 33 & Toluene & $320,405,576(69600)$ & & & & [30] \\
\hline 34 & Toluene & $350,405,586(69200)$ & & & & [30] \\
\hline 35 & Chloroform & $310,602(66000)$ & & & & {$[8]$} \\
\hline 36 & Chloroform & $310,530,653(70000)$ & & & & [8] \\
\hline 37 & Chloroform & $310,602(65000)$ & & & & {$[8]$} \\
\hline 38 & Chloroform & $310,500,651(67000)$ & & & & {$[8]$} \\
\hline 39 & Chloroform & 465,530 (6309), 610 & & & & [29] \\
\hline 40 & Chloroform & 436 (15848), 554 (25118), 646 & & & & [29] \\
\hline 41 & Chloroform & 478 (12589), 561 (19952), 668 & & & & [29] \\
\hline 42 & Chloroform & 478 (10000), 570 (19952), 690 & & & & [29] \\
\hline 43 & Toluene & 531 (46773), $613(15488)$ & & & & [33] \\
\hline 44 & Toluene & 558 (26302), 680 (20417) & 612 & 0.31 & 5.2 & [33] \\
\hline \multirow[t]{2}{*}{45} & Toluene & $430,538(44000)$ & & & & [13] \\
\hline & & $430,538(74622)$ & & & & [24] \\
\hline 46 & Toluene & $505(44668)$ & & & & [33] \\
\hline 47 & DCM & $310,350,505(63400)$ & 518 & 0.08 & $\begin{array}{l}0.64(19.0 \%) \\
2.78(81.0 \%)\end{array}$ & [12] \\
\hline
\end{tabular}


Continuation of Table 1.

\begin{tabular}{|c|c|c|c|c|c|c|}
\hline Compounds & Solvent & $\lambda_{\mathrm{abs}}, \mathrm{nm}\left(\varepsilon, \mathrm{M}^{-1} \cdot \mathrm{cm}^{-1}\right)$ & $\lambda_{\mathrm{em}}, \mathrm{nm}$ & $\Phi$ & $\tau, \mathrm{ns}$ & Ref. \\
\hline & DCM & $260,310,350,498$ & 516 & 0.18 & & {$[32]$} \\
\hline 48 & Toluene & $360,512(46000)$ & & & & {$[13]$} \\
\hline 49 & Toluene & $440,544(108769)$ & & & & [24] \\
\hline 50 & Toluene & $420,546(88977)$ & & & & [24] \\
\hline \multirow[t]{2}{*}{51} & Toluene & $440,550(47000)$ & & & & [13] \\
\hline & Toluene & $440,551(103285)$ & 571 & 0.001 & & [24] \\
\hline 52 & Toluene & $350,567(34000)$ & & & & {$[13]$} \\
\hline 53 & Toluene & $390,561(49000)$ & & & & {$[13]$} \\
\hline 54 & Toluene & $350,521(45000)$ & & & & {$[13]$} \\
\hline 55 & Toluene & $300,706(80000)$ & & & $1.7(\mathrm{~ns}), 4.8(\mu \mathrm{s})$ & [17] \\
\hline 56 & $\mathrm{DCM}$ & $330,418(52000)$ & & & & [21] \\
\hline 57 & DCM & $330,419(51000)$ & & & & [21] \\
\hline 58 & DCM & $330,455(57000)$ & & & & [21] \\
\hline 59 & DCM & $330,455(65000)$ & & & & [21] \\
\hline 60 & Chloroform & $519(169824)$ & & & 0.5 & [20] \\
\hline 61 & Toluene & $360,480,504(77800)$ & 514 & 8.3 & $\begin{array}{c}0.42(65 \%) \\
4.29(14.8 \%)\end{array}$ & [12] \\
\hline 62 & Toluene & $390,500,538(80200)$ & 551 & 4.9 & $\begin{array}{l}0.18(91 \%) \\
4.73(8.3 \%)\end{array}$ & [12] \\
\hline 63 & DCM & 592 (42000), 367 (23800) & & & & [7] \\
\hline 64 & DCM & 581 (92000), 398 (10400) & 607 & & 0.0146 & [7] \\
\hline 65 & DCM & 652 (58000), $331(23800)$ & & & & [7] \\
\hline 66 & DCM & $586(81000), 410(7900)$ & & & & [7] \\
\hline 67 & DCM & 647 (55000), 333 (29300) & & & & [7] \\
\hline 68 & DCM & 651 (106000), 313 (18400) & 675 & & 0.1349 & [7] \\
\hline 69 & PBS & 376 (41686), 443 (15135), 662 (74131) & 684 & 0.03 & & {$[14]$} \\
\hline 70 & PBS & 376 (41686), 441 (15135), 662 (75857) & 685 & 0.03 & & {$[14]$} \\
\hline 71 & PBS & 377 (40738), 443 (14791), 662 (75857) & 685 & 0.04 & & {$[14]$} \\
\hline 72 & & 376 (41686), 441 (15135), 662 (75857) & 686 & 0.03 & & {$[14]$} \\
\hline 73 & $\mathrm{PhCN}$ & $300,475,635$ & 720 & & & [23] \\
\hline 74 & $\mathrm{PhCN}$ & $300,475,635$ & 735 & & & [23] \\
\hline 75 & DCB & $425,550,590$ & $520,602,650$ & & 0.0168 & [19] \\
\hline 76 & $\mathrm{H}_{2} \mathrm{O}: \mathrm{EtOH}, 50: 50$ & $\begin{aligned} & 275(25400), 352(18000), 478(23600), \\
& 540(13800)\end{aligned}$ & & & & [37] \\
\hline 77 & $\mathrm{H}_{2} \mathrm{O}: \mathrm{EtOH}, 50: 50$ & 339 (12300), 480 (12100), 530 (8400) & & & & [37] \\
\hline 78 & $\mathrm{H}_{2} \mathrm{O}: \mathrm{EtOH}, 50: 50$ & $\begin{array}{c}323(53600), 393(10100), 475(23600), \\
532(8400)\end{array}$ & & & & [37] \\
\hline 79 & $\mathrm{H}_{2} \mathrm{O}: \mathrm{EtOH}, 50: 50$ & $\begin{array}{c}298(35000), 343(29400), 414(14500), \\
509(61500), 598(54000)\end{array}$ & & & & [37] \\
\hline 80 & $\mathrm{H}_{2} \mathrm{O}: \mathrm{EtOH}, 50: 50$ & $\begin{array}{c}298(25800), 343(29200), 414(14100), \\
509(61000), 598(53000)\end{array}$ & & & & [37] \\
\hline 81 & $\mathrm{H}_{2} \mathrm{O}: \mathrm{EtOH}, 50: 50$ & $\begin{array}{c}298(102400), 343(14200), 414(1800), \\
509(10600)\end{array}$ & & & & [37] \\
\hline 82 & DCM & $\begin{aligned} & 280(13600), 335(27800), 475(20000), \\
& 540(10800)\end{aligned}$ & & & & [38] \\
\hline 83 & DCM & $\begin{array}{c}305(31600), 345(13300), 422(4800) \\
510(17200)\end{array}$ & & & & [38] \\
\hline 84 & DCM & 344,503 & & & & [36] \\
\hline 85 & $\mathrm{DCM}$ & 344,514 & & & & [36] \\
\hline 86 & DCM & 348,483 & & & & [36] \\
\hline 87 & DCM & 347,494 & & & & [36] \\
\hline
\end{tabular}




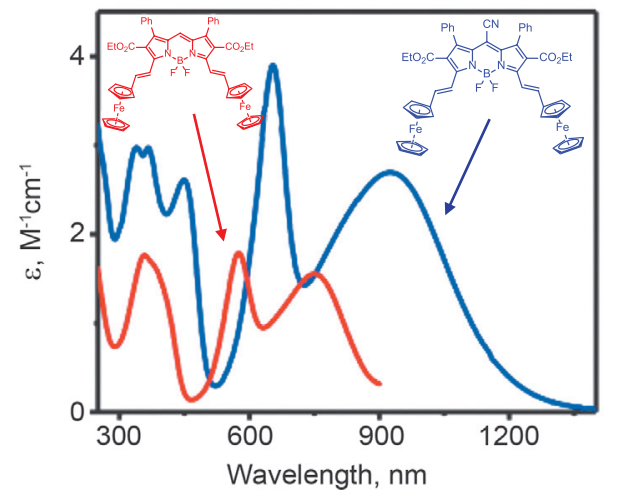

Figure 8. UV-Vis-NIR spectra of diferrocenyl-containing BODIPYs 13 and 15. ${ }^{[9,16]}$

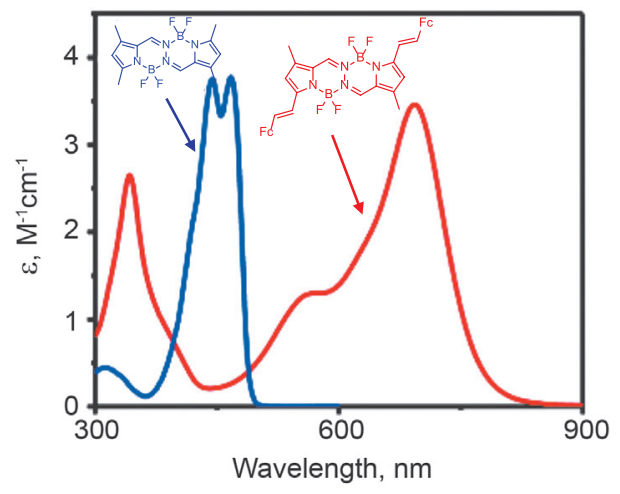

Figure 9. UV-Vis-NIR spectra of ferrocenyl-containing BOPHY and its BOPHY precursor. ${ }^{[18]}$

strong low-energy band, which dominates the UV-Vis-NIR spectrum and is predominantly MLCT in character (Figure 9). While the energy of the predominantly ferrocenecentered HOMO is fairly constant (as indicative from the electrochemical data), the energy of the chromophore-centered LUMO can be more easily tuned by electron-donating or electron-withdrawing substituents on the core $\pi$-system. In particular, a large contribution from the meso-atom of BODIPY or aza-BODIPY to the LUMO makes this orbital susceptible for fine tuning. Indeed, introduction of the cyano group at the meso-position of diferrocenyl-containing BODIPY 15 $^{[9]}$ results in significant stabilization of the LUMO energy and dramatic low-energy shift of MLCT and $\pi-\pi^{*}$ bands in this compound compared to the parent BODIPY 13 (Figure 8). ${ }^{[16]}$

\section{Fluorescence and Photo-Induced Electron-Transfer Properties}

Taking into consideration predominant ferrocenecentered nature of the HOMO, it is not surprising that the steady-state fluorescence in ferrocene-containing BODIPYs and their analogues are either completely quenched or severely suppressed because of the electron-transfer from

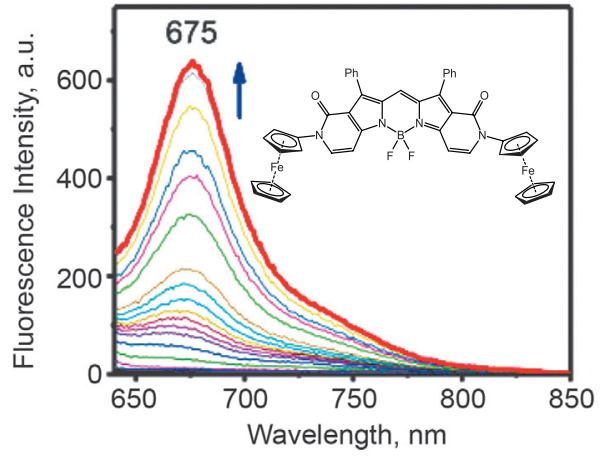

Figure 10. Typical partial restoration of fluorescence in ferrocenyl-containing BODIPYs. Modified from reference ${ }^{[7]}$.

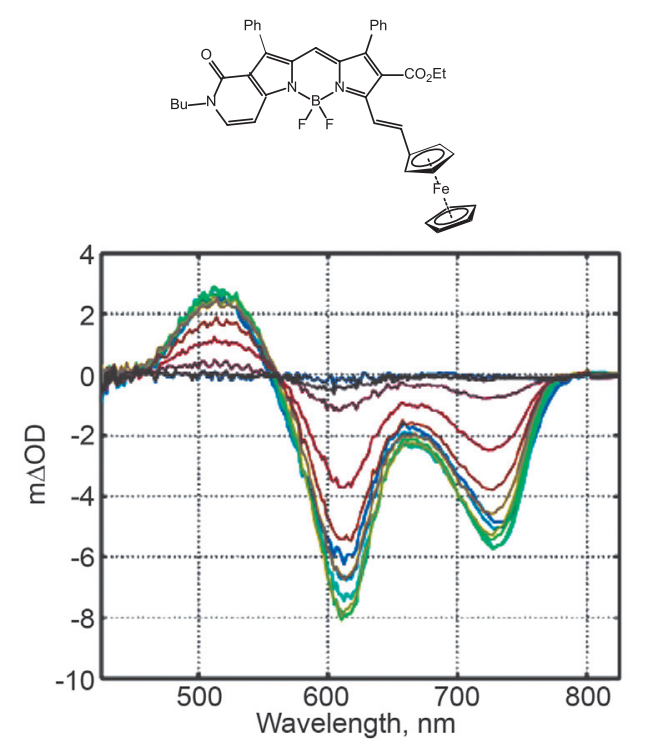

Figure 11. Typical transient absorption spectrum of ferrocenylcontaining BODIPYs. Modified from reference ${ }^{[16]}$.

the HOMO to the hole created upon photoexcitation of the chromophore's $\pi$-system (Table 1). Oxidation of the ferrocene substituent(s) in BODIPYs and their analogues under chemical or spectroelectrochemical oxidation conditions reduces the effectiveness of such electron-transfer pathway and results in partial restoration of the fluorescence, which can be again suppressed by the reduction of ferricinium group to ferrocene (Figure 10). ${ }^{[7,10,11,16,17,25,29,33]}$ Similar partial restoration of the steady-state fluorescence was also reported for ferrocene-containing BODIPY system in viscous solvents $^{[32]}$ and upon addition of water ${ }^{[28]}$ to a solution of some ferrocene-containing BODIPYs. It was speculated that the dihedral angle (and thus degree of conjugation between ferrocene group and chromophore's $\pi$-system) is responsible for the fluorescence increase in the former case, while partial degradation of the organometallic fragment is responsible for fluorescence increase in the latter. Similar cleavage of the ferrocene-chromophore chemical bonds under biological conditions was thought to be responsible for fluorescence increase in BODIPY-ferrocene conjugates 22 and 23, ${ }^{[14,15]}$ which were proposed as platforms for selective bioimaging applications. Available transient absorption data on 
ferrocene-BODIPY dyads and their analogues are suggestive of ultrafast electron-transfer from the organometallic fragment to the photoexcited antennae with the formation of a $\mathrm{Fc}^{+}$-BODIPY ${ }^{-}$charge-separated state (Figure 11). ${ }^{[7,16]}$ The formation of BODIPY-centered anion-radical species upon excitation of the ferrocene-BODIPY dyads was also reported on the basis of flash photolysis experiments. In the majority of cases, such charge-separated states undergo direct recombination to the ground state (Table 1). Ferrocene-containing aza-BODIPY dyad 55, ${ }^{[17]}$ however, behaves quite differently. Indeed, upon excitation, this system rapidly forms a charge-separated state followed by subpicosecond charge recombination to form a long-lived $(4.8 \pm 0.1 \mathrm{~ms})$ triplet state (Figure 12). The formation of long-lived chargeseparation states in ferrocene-BODIPY- $\mathrm{C}_{60}$ and ferroceneaza-BODIPY- $\mathrm{C}_{60}$ triads upon photoexcitation of the organic chromophore is also well-documented. In these cases, lifetimes up to $500 \mathrm{ps}$ were observed for $\mathrm{Fc}^{+}$-BODIPY- $\mathrm{C}_{60}{ }^{--}$photoinduced states, which makes such triads prospective lighharvesting modules. In the case of Fc-aza-BODIPY- $\mathrm{C}_{60}$ systems 73 and 74, ${ }^{[23]}$ the photoexcitation of $\mathrm{C}_{60}$ acceptor results in formation of a $\mathrm{Fc}^{+}$-azaBODIPY- $\mathrm{C}_{60}{ }^{--}$charge-separated state, while photoexcitation of aza-BODIPY core leads to formation of $\mathrm{Fc}^{+}$-azaBODIPY ${ }^{--}-\mathrm{C}_{60}$ charge-separated state. Overall, all available photochemical data obtained thus far on ferrocene-BODIPYs and their analogues are indicative of the effective electro-donating properties of ferrocene
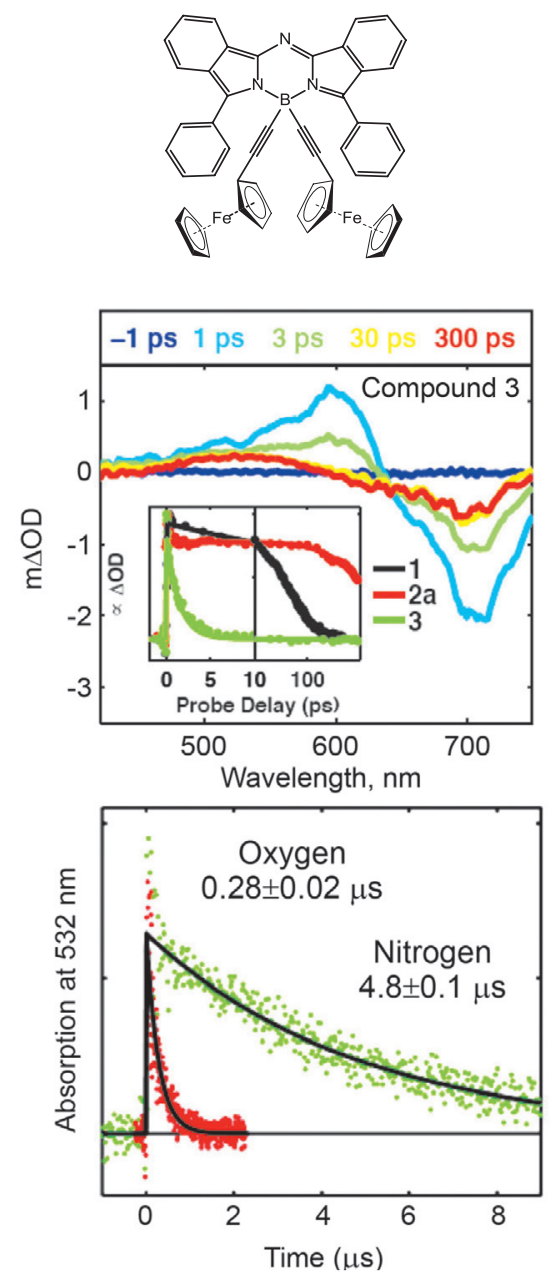

Figure 12. Transient absorption data and time-dependent decay profiles for aza-BODIPY 55. Modified from reference ${ }^{[17]}$. fragment, which is important for imaging, bioimaging, and light-harvesting applications.

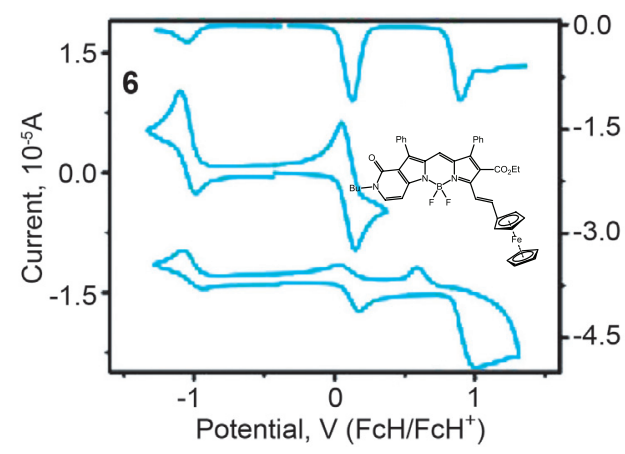

Figure 13. Typical DPV (top) and CV (middle and bottom) data for ferrocenyl-containing BODIPYs. Modified from reference ${ }^{[16]}$.

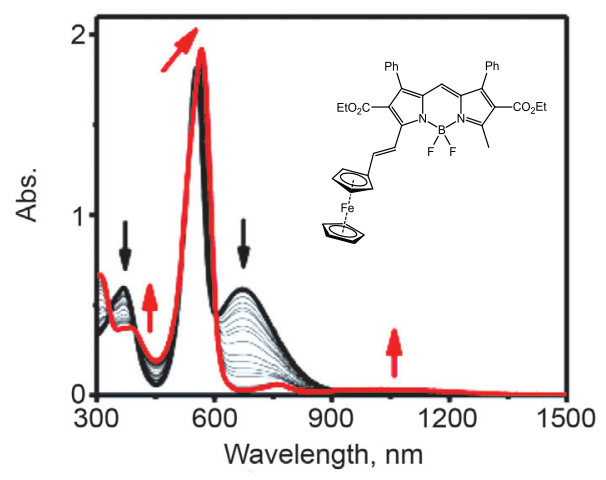

Figure 14. Typical spectroelectrochemical data upon oxidation of the ferrocenyl-containing BODIPYs. Decay of the low-energy MLCT band is indicative of ferrocene-centered oxidation. Modified from reference ${ }^{[16]}$.

\section{Redox Processes}

In all monoferrocenyl derivatives studied by electrochemical and, in some cases, spectroelectrochemical or chemical oxidation methods, the first oxidation process was attributed to the oxidation of ferrocene fragment (Table 2). Usually, additional irreversible oxidation and reversible reduction processes centered at the BODIPY or aza-BODIPY core are also observed in electrochemical experiments on these compounds (Figure 13). Assignment of the first oxidation process was not only confirmed on the basis of similarity of the oxidation potential of unsubstituted ferrocene, but also, in some cases, on the basis of spectroelectrochemical and chemical oxidation data. In a typical case presented in Figure 14, during the first oxidation of compound $\mathbf{1 6}^{[16]}$ under spectroelectrochemical conditions, the broad MLCT band loses intensity, while the most intense $\pi-\pi^{*}$ transition undergoes a small low-energy shift and increases in intensity, which is clearly indicative of the ferrocene fragment oxidation. An interesting situation was observed in BODIPY 17 ${ }^{[16]}$ 
because both the ferrocene and $N, N$-diaminophenyl fragments undergo single-electron reversible oxidation processes. The separation between these two oxidation potentials is $340 \mathrm{mV}$ in the DCM/0.05M TBA $\left[\mathrm{B}\left(\mathrm{C}_{6} \mathrm{~F}_{5}\right)_{4}\right]$ electrolyte system and $250 \mathrm{mV}$ in DCM/0.1M TBAP system. Stepwise oxidation of compound $\mathbf{1 7}$ under spectroelectrochemical conditions is indicative of the first oxidation of the ferrocene fragment as the most intense $\pi-\pi^{*}$ transition undergoes only small changes, while the second oxidation process is clearly affecting chromophore's $\pi$-system and can be attributed to the oxidation of the $N, N$-dimethylaminophenyl group (Figure 15). In contrast, oxidation of this compound with $\mathrm{Fe}\left(\mathrm{ClO}_{4}\right)_{3}$ results in appearance of two new bands observed at 604 and $743 \mathrm{~nm}$, which resembles the UV-Vis spectrum of monoferrocenyl BODIPY 16 and is indicative of the oxidation of the $N, N$ dimethylaminophenyl fragment (Figure 16). Although such behavior is yet to be explained, it is suggestive of the very small energy difference between BODIPY- and ferrocenecentered orbitals, which can be altered by the high concentration of electrolyte (salt effect) and/or the Lewis acidity of the $\mathrm{Fe}^{3+}$ ion, which can interact with an electron-rich nitrogen atom of the $N, N$-dimethylaminophenyl group.

Similar to the monoferrocenyl derivatives, diferrocenyl BODIPYs and their analogues with ferrocene fragments, which are not conjugated into the chromophore's $\pi$-system, exhibit a single oxidation process associated with simultaneous oxidation of both ferrocene groups. ${ }^{[14,23]}$ Such behavior is not surprising as the efficient electron-transfer pathway between two organometallic sites cannot be established in this case. It is interesting that a $\sim 100 \mathrm{mV}$ separation between the first and the second oxidation waves is observed in azaBODIPY 55 ${ }^{[17]}\left(\mathrm{DCM} / 0.05 \mathrm{M}\right.$ TBA[B $\left.\left(\mathrm{C}_{6} \mathrm{~F}_{5}\right)_{4}\right]$ electrolyte system). Spectroelectrochemical data, however, did not confirm electronic coupling between two ferrocene fragments and thus such separation in oxidation potentials was attributed to the ion-pairing effect. In contrast, the ferrocene-centered oxidation processes in diferrocenyl BODIPYs $\mathbf{1 3}^{[16]}$ and $\mathbf{1 4}{ }^{[25]}$ are well-separated $\left(170 \mathrm{mV}\right.$ in the $\mathrm{DCM} / 0.05 \mathrm{M} \mathrm{TBA}\left[\mathrm{B}\left(\mathrm{C}_{6} \mathrm{~F}_{5}\right)_{4}\right]$

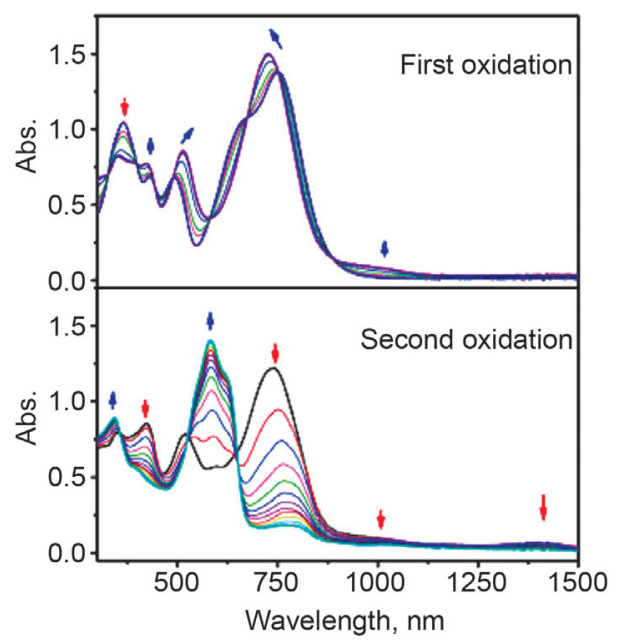

Figure 15. Stepwise oxidation of the BODIPY 16 under spectroelectrochemical conditions. The first process is indicative of the ferrocene oxidation, while the second process is indicative of the oxidation of dimethylaminophenyl group. Modified from reference ${ }^{[16]}$

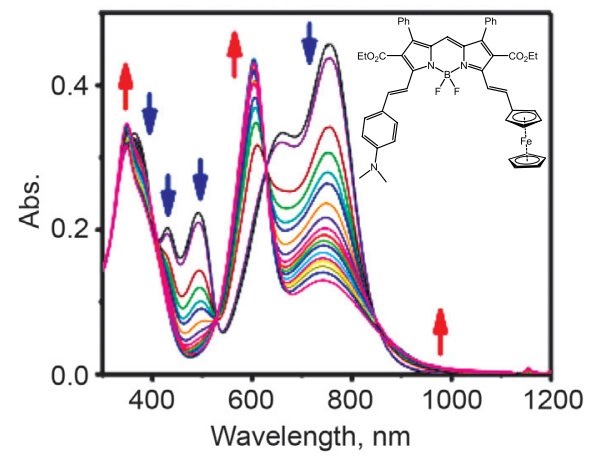

Figure 16. Oxidation of the BODIPY 16 under chemical oxidation conditions. Observed transformation is indicative of the oxidation of dimethylaminophenyl group. Modified from reference ${ }^{[16]}$.

electrolyte system) and spectroelectrochemical data are clearly suggestive of the formation of the mixed-valence complexes $[\mathbf{1 3}]^{+}$and $[\mathbf{1 4}]^{+}$. Although one might speculate that thoughspace Fe-Fe distance in this compound is about twice as small as a through-bond electron-transfer pathway, this dilemma was solved in the case of diferrocenyl BOPHY $\mathbf{2 6}^{[18]}$ in which the though-space and through-bonds electron-transfer distances are nearly equivalent $(\sim 17.2 \AA)$. CV and DPV data on BOPHY 26 shows a $200 \mathrm{mV}$ separation between the first and the second oxidation processes $\left(\mathrm{DCM} / 0.05 \mathrm{M} \mathrm{TBA}\left[\mathrm{B}\left(\mathrm{C}_{6} \mathrm{~F}_{5}\right)_{4}\right]\right.$ electrolyte system), while spectroelectrochemical and chemical oxidation experiments are suggestive of the formation of the mixed-valence $[\mathbf{2 6}]^{+}$cation (Figure 17). Band deconvolution analysis of the NIR portion of the $[\mathbf{2 6}]^{+}$spectrum indicative of Class II spin-localized behavior using the Robin-Day classification.

The redox properties of the di- and triferrocenyl-containing BODIPYs with ferrocene fragments attached via $-\mathrm{C} \equiv \mathrm{C}$ - linking groups are indicative of the lack of electronic communication between redox centers. ${ }^{[29]}$ It is interesting to note that even in the case of triferrocenyl BODIPY $\mathbf{4 2},{ }^{[29]}$ authors observed only one simultaneous three-electron oxidation process in electrochemical experiments.

The redox properties of differrocenyl and tetraferrocenyl aza-BODIPYs and the corresponding azadipyrromethenes 1-8 in which ferrocene fragments are directly linked to the

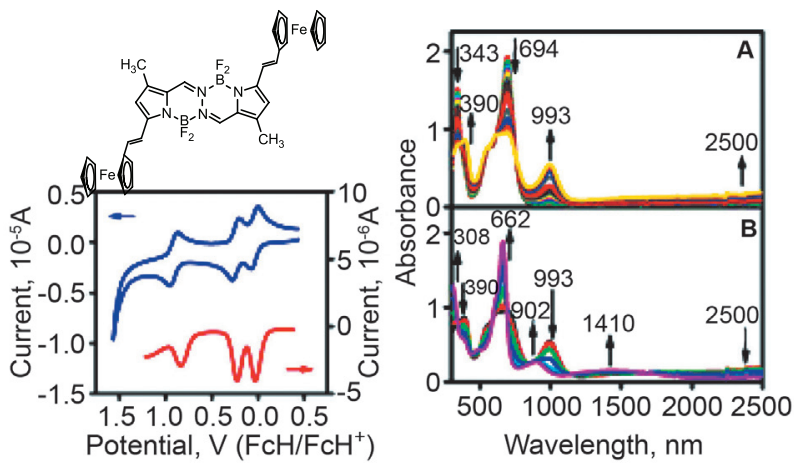

Figure 17. Electrochemical (left, CV in blue and DPV in red) and spectroelectrochemical (right, the first oxidation in on a top and a second oxidation is on a bottom) data on BOPHY 26. Adapted from reference ${ }^{[18]}$. 

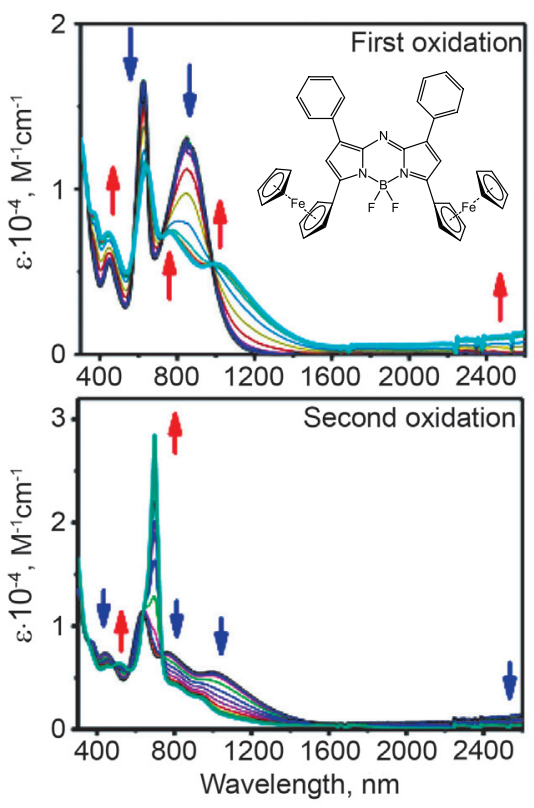

Figure 18. First (top) and second (bottom) oxidation of the azaBODIPY 7 under spectroelectrochemical conditions. Modified from reference ${ }^{[22]}$.

aza-BODIPY $\pi$-system are quite illustrative. ${ }^{[6,10,22]}$ In case of the differocenyl compounds $\mathbf{3}$ and $7^{[22]}$ with ferrocene groups located at the $\alpha$-pyrrolic $(3,5-)$ positions, electrochemical experiments support the presence of the metal-metal coupling since the first and the second oxidation waves are separated by 460 and $340 \mathrm{mV}$, respectively, in the $\mathrm{DCM} / 0.05 \mathrm{M}$ $\mathrm{TBA}\left[\mathrm{B}\left(\mathrm{C}_{6} \mathrm{~F}_{5}\right)_{4}\right]$ electrolyte system. In addition, spectroelectrochemical and chemical oxidation data on these compounds is suggestive of the formation of the mixed-valence complexes $[3]^{+}$and $[7]^{+}$based on the appearance of a broad NIR band (Figure 18). Similar differocenyl complexes 1, 2, 5, $\mathbf{6}^{[10]}$ with ferrocene groups located at $\beta$-pyrrolic $(1,7-)$ positions were investigated by electrochemical (CV) method only in the DCM/0.1M TBAP electrolyte system. In their original communication, authors listed only one redox potential associated with the simultaneous oxidation of both ferrocene fragments, while their graphical electrochemical data, at least for the phenyl derivatives $\mathbf{1}$ and 5, clearly show two closely spaced sequential processes for ferrocene fragment oxidation, which are indicative of potential electronic coupling in these compounds. ${ }^{[10]}$ Based on electrochemical data, however, the metalmetal coupling in $\beta$-substituted systems is smaller compared to the $\alpha$-substituted analogues, which is not surprising as the atomic orbital contributions from the $\alpha$-pyrrolic carbon atoms to the HOMO of the aza-BODIPY core are larger compared to similar contributions from the $\beta$-pyrrolic carbon atoms. In case of the tetraferrocenyl-containing aza-BODIPY $\mathbf{8}$ and the corresponding azadipyrromethene analogue $4,{ }^{[6]}$ four sequential single-electron oxidation processes were observed in $\mathrm{CV}$ and DPV experiments in the DCM/0.05M TBA $\left[\mathrm{B}\left(\mathrm{C}_{6} \mathrm{~F}_{5}\right)_{4}\right]$ as well as the DCM/0.1M TBAP electrolyte systems (Figure 19). Based on the spectroelectrochemical (Figure 20), chemical oxidation, Mössbauer, (Figure 21) and DFT data, it was concluded that the first oxidation process is localized at one of the ferrocene fragments attached to the $\alpha$-pyrrolic carbon and all the mixed-valence $[4]^{\mathrm{n}+}$ and $[\mathbf{8}]^{\mathrm{n}+}$ species belong to the Class II intermediate category in the Robin-Day classification.

Based on the electrochemical data available for ferrocene-containing BODIPYs and their analogues (Table 2), one might conclude that the first oxidation potential associated with the ferrocene fragment(s) is always observed in a quite narrow window of potentials. Such behavior is not surprising, as the systems with ferrocene fragments that are not conjugated in the chromophore's $\pi$-system as well the systems, in which the ferrocene groups are connected to the chromophore $\pi$-system via $-\mathrm{C} \equiv \mathrm{C}$ - linking fragments, are expected to have the HOMO localized to a large degree at the ferrocene- or ferrocene-linking groups. Thus, the value of the first oxidation potential to a large extent is dictated by the electronic structure of ferrocene or ferrocene-linking group. On the other hand, in the case of ferrocene-containing BODIPYs and their analogues in which the ferrocene
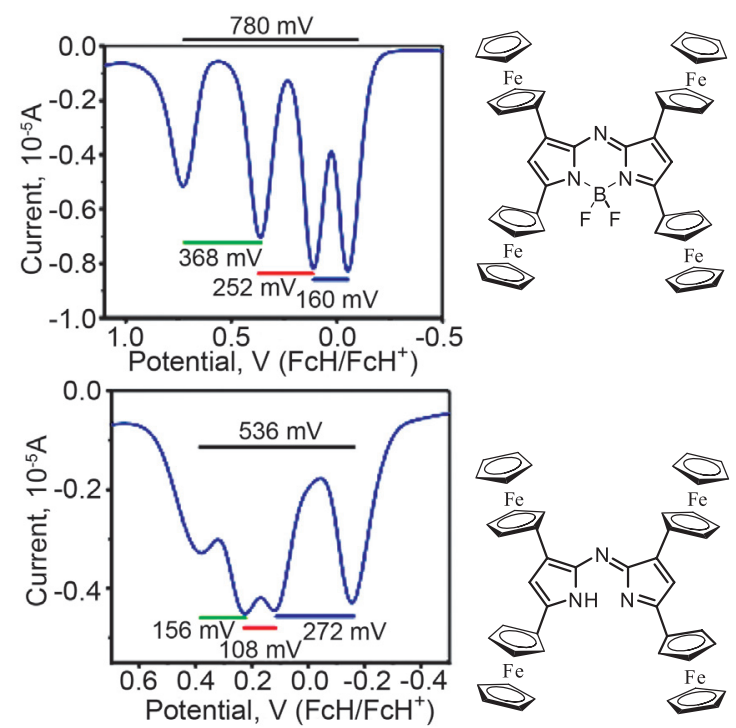

Figure 19. DPV data for $\mathbf{4}$ and $\mathbf{8}$ in the ferrocene oxidation region. Modified from reference ${ }^{[6]}$.

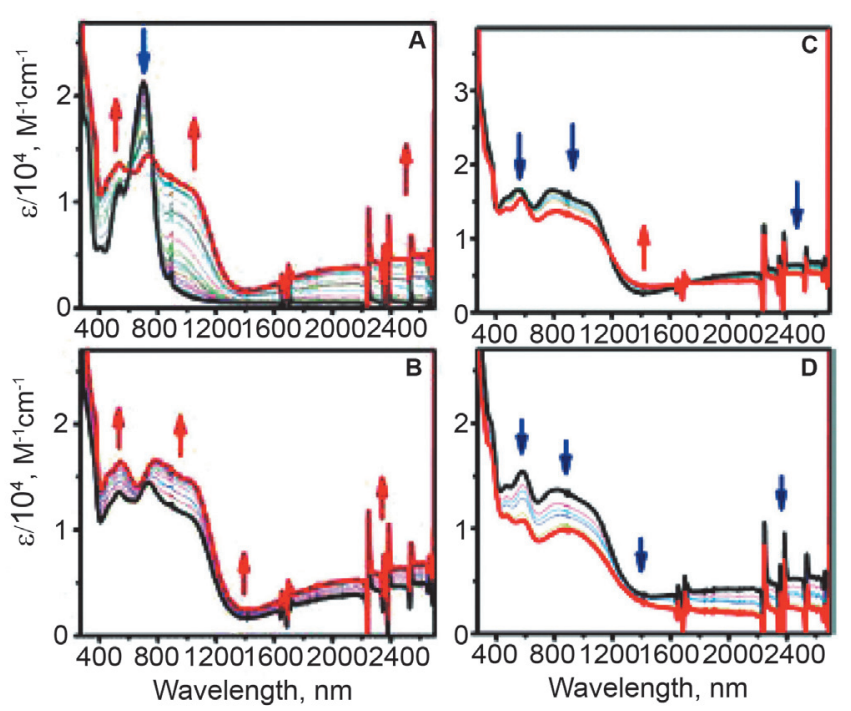

Figure 20. Stepwise oxidation of $\mathbf{8}$ to $[\mathbf{8}]^{+}(\mathrm{A}),[\mathbf{8}]^{+}$to $[\mathbf{8}]^{2+}(\mathrm{B})$, $[\mathbf{8}]^{2+}$ to $[\mathbf{8}]^{3+}(\mathrm{C})$, and $[\mathbf{8}]^{3+}$ to $[\mathbf{8}]^{4+}(\mathrm{D})$. Modified from reference ${ }^{[6]}$. 
Ferrocenyl-Containing BODIPYs, aza-BODIPYs, BOPHYs, Transition-Metal Dipyrromethenes and aza-Dipyrromethenes

Table 2. Redox properties of ferrocenyl-containing BODIPYs and their analogues.

\begin{tabular}{|c|c|c|c|c|c|c|c|c|c|c|}
\hline Compounds & System & Ref. & $E^{4}{ }_{\mathrm{Ox}}(\mathrm{V})$ & $E_{\mathrm{Ox}}^{3}(\mathrm{~V})$ & $E_{\text {Ox }}^{2}(\mathrm{~V})$ & $E_{\text {Ox }}^{1}(\mathrm{~V})$ & $E_{\text {Red }}^{1}(\mathrm{~V})$ & $E_{\text {Red }}^{2}(\mathrm{~V})$ & $E_{\text {Red }}^{3}(\mathrm{~V}) E_{\text {Red }}^{4}(\mathrm{~V})$ & Ref. \\
\hline 1 & DCM / 0.1M TBAP & SCE & & & & 0.53 & -0.99 & -1.46 & & {$[10]$} \\
\hline 2 & DCM / 0.1M TBAP & SCE & & & & 0.52 & -0.88 & -1.45 & & {$[10]$} \\
\hline 3 & $\mathrm{DCM} / 0.05 \mathrm{M}$ TBAF & $\mathrm{Fc} / \mathrm{Fc}^{+}$ & & & 0.35 & 0.01 & -1.42 (irr) & & & [22] \\
\hline 4 & DCM / 0.05M TFAB & $\mathrm{Fc} / \mathrm{Fc}^{+}$ & 0.39 & 0.24 & 0.14 & -0.14 & & & & [6] \\
\hline 5 & $\mathrm{DCM} / 0.1 \mathrm{M}$ TBAP & SCE & & & & 0.62 & -0.56 & -1.29 & & {$[10]$} \\
\hline 6 & DCM / 0.1M TBAP & SCE & & & & 0.59 & -0.55 & -1.35 & & {$[10]$} \\
\hline 7 & $\mathrm{DCM} / 0.05 \mathrm{M}$ TBAF & $\mathrm{Fc} / \mathrm{Fc}^{+}$ & & & 0.45 & 0.01 & -1.15 & & & [22] \\
\hline 8 & DCM / 0.05M TFAB & $\mathrm{Fc} / \mathrm{Fc}^{+}$ & 0.71 & 0.35 & 0.09 & -0.07 & -1.31 & & & {$[6]$} \\
\hline 9 & DCM / 0.1M TBAP & SCE & & & 1.56 (irr) & 0.74 & -0.8 & & & [33] \\
\hline 11 & $\mathrm{DCM} / 0.1 \mathrm{M} \mathrm{TBAPF}_{6}$ & $\mathrm{Ag} / \mathrm{Ag}^{+}$ & & & 1.13 & 0.42 & -1.33 & & & {$[32]$} \\
\hline 12 & $\mathrm{DCM} / 0.1 \mathrm{M} \mathrm{TBAPF}_{6}$ & $\mathrm{Ag} / \mathrm{Ag}^{+}$ & & & & 0.55 & -0.95 & & & [34] \\
\hline 13 & DCM / 0.1M TBAP & $\mathrm{Fc} / \mathrm{Fc}^{+}$ & & 1.29 (irr) & 0.17 & 0.02 & -1.21 (irr) & & & {$[16]$} \\
\hline 14 & $\mathrm{DCM} / 0.1 \mathrm{M} \mathrm{TBAPF}{ }_{6}$ & $\mathrm{Ag} / \mathrm{Ag}^{+}$ & & & 0.75 & 0.05 & -1.32 & & & [25] \\
\hline 15 & DCM / 0.05M TFAB & $\mathrm{Fc} / \mathrm{Fc}^{+}$ & & & 0.21 & 0.03 & -0.80 & -1.70 & & [9] \\
\hline 16 & DCM / 0.1M TBAP & $\mathrm{Fc} / \mathrm{Fc}^{+}$ & & & 0.56 (irr) & 0.08 & -1.19 (irr) & & & {$[16]$} \\
\hline 17 & $\mathrm{DCM} / 0.1 \mathrm{M}$ TBAP & $\mathrm{Fc} / \mathrm{Fc}^{+}$ & & 0.90 (irr) & 0.39 & 0.05 & -1.26 (irr) & & & {$[16]$} \\
\hline 18 & DCM / 0.1M TBAP & $\mathrm{Fc} / \mathrm{Fc}^{+}$ & & & 0.98 & 0.10 & -1.04 (irr) & & & {$[16]$} \\
\hline 19 & $\mathrm{PhCN} / 0.1 \mathrm{M}$ TBAP & SCE & & & & 0.50 & -0.996 & & & [27] \\
\hline 20 & $\mathrm{PhCN} / 0.1 \mathrm{M}$ TBAP & SCE & & & & 0.50 & -0.576 & -0.996 & & [27] \\
\hline 24 & DCM / 0.1M TBAP & $\mathrm{Fc} / \mathrm{Fc}^{+}$ & & & 0.174 & 0 (irr) & -1.38 (irr) & -2.1 (irr) & & [35] \\
\hline 25 & $\mathrm{DCM} / 0.1 \mathrm{M}$ TBAP & $\mathrm{Fc} / \mathrm{Fc}^{+}$ & & & 0.23 & 0 (irr) & -1.35 (irr) & & & [35] \\
\hline 26 & $\mathrm{DCM} /$ 0.05M TBAF & $\mathrm{Fc} / \mathrm{Fc}^{+}$ & & 0.906 & 0.236 & 0.032 & & & & [18] \\
\hline 27 & $\mathrm{AN} / 0.01 \mathrm{M} \mathrm{TBAPF}{ }_{6}$ & $\mathrm{Ag} / \mathrm{Ag}^{+}$ & & & & 0.55 & -0.95 & & & {$[11]$} \\
\hline 31 & $\mathrm{DCM} / 0.1 \mathrm{M} \mathrm{TBAPF}_{6}$ & $\mathrm{SCE}$ & & & 1.24 (irr) & 0.53 & -1.05 & & & [30] \\
\hline 32 & $\mathrm{DCM} / 0.1 \mathrm{M} \mathrm{TBAPF}{ }_{6}$ & SCE & & & 1.21 (irr) & 0.52 & -1.06 & & & {$[30]$} \\
\hline 33 & $\mathrm{DCM} / 0.1 \mathrm{M} \mathrm{TBAPF}_{6}$ & SCE & & & 1.20 (irr) & 0.44 & -1.08 & & & {$[30]$} \\
\hline 34 & $\mathrm{DCM} / 0.1 \mathrm{M} \mathrm{TBAPF}{ }_{6}$ & SCE & & & 1.21 (irr) & 0.51 & -1.06 & & & [30] \\
\hline 35 & DCM / 0.1M TBAPF 6 & $\mathrm{Fc} / \mathrm{Fc}^{+}$ & & & 1.03 (irr) & 0.13 & -1.56 & -2.18 & & {$[8]$} \\
\hline 36 & $\mathrm{DCM} / 0.1 \mathrm{M} \mathrm{TBAPF}{ }_{6}$ & $\mathrm{Fc} / \mathrm{Fc}^{+}$ & & & 1.06 (irr) & 0.14 & -1.51 & -2.07 & & {$[8]$} \\
\hline 37 & $\mathrm{DCM} / 0.1 \mathrm{M} \mathrm{TBAPF}_{6}$ & $\mathrm{Fc} / \mathrm{Fc}^{+}$ & & & 1.02 (irr) & 0.12 & -1.18 & -1.51 & & {$[8]$} \\
\hline 38 & $\mathrm{DCM} / 0.1 \mathrm{M} \mathrm{TBAPF}{ }_{6}$ & $\mathrm{Fc} / \mathrm{Fc}^{+}$ & & & 1.09 (irr) & 0.13 & -0.80 & -1.47 & -2.02 & {$[8]$} \\
\hline 39 & DCM / 0.1M TBAP & $\mathrm{Fc} / \mathrm{Fc}^{+}$ & & & & 0.696 & -0.616 & & & [29] \\
\hline 40 & $\mathrm{DCM} / 0.1 \mathrm{M}$ TBAP & $\mathrm{Fc} / \mathrm{Fc}^{+}$ & & & & 0.650 & -0.625 & & & [29] \\
\hline 41 & DCM / 0.1M TBAP & $\mathrm{Fc} / \mathrm{Fc}^{+}$ & & & & 0.664 & -0.568 & & & [29] \\
\hline 42 & DCM / 0.1M TBAP & $\mathrm{Fc} / \mathrm{Fc}^{+}$ & & & & 0.653 & -0.541 & & & [29] \\
\hline 43 & DCM / 0.1M TBAP & SCE & & & 1.57 (irr) & 0.64 & -0.74 & & & [33] \\
\hline 44 & DCM / 0.1M TBAP & SCE & & & 1.36 (irr) & 0.64 & -0.70 & & & {$[33]$} \\
\hline 45 & DCM / 0.1M TBAPF 6 & $\mathrm{Fc} / \mathrm{Fc}^{+}$ & & & 1.03 (irr) & 0.25 & -1.01 (irr) & -1.28 (irr) & & {$[13,24]$} \\
\hline 46 & DCM / 0.1M TBAP & SCE & & & & 0.617 & -0.71 & & & [33] \\
\hline \multirow[t]{2}{*}{47} & $\mathrm{DCM} / 0.1 \mathrm{M} \mathrm{TBAPF}{ }_{6}$ & $\mathrm{Ag} / \mathrm{Ag}^{+}$ & & & 0.97 & 0.32 & -1.50 & & & {$[12]$} \\
\hline & $\mathrm{DCM} / 0.1 \mathrm{M} \mathrm{TBAPF}_{6}$ & SCE & & & 1.16 & 0.52 & -1.24 & & & {$[32]$} \\
\hline 48 & $\mathrm{DCM} / 0.1 \mathrm{M} \mathrm{TBAPF}{ }_{6}$ & $\mathrm{Fc} / \mathrm{Fc}^{+}$ & & & 1.17 (irr) & 0.10 & -1.12 (irr) & -1.41 (irr) & & [13] \\
\hline 49 & $\mathrm{DCM} / 0.1 \mathrm{M} \mathrm{TBAPF}_{6}$ & $\mathrm{Fc} / \mathrm{Fc}^{+}$ & & & 1.09 (irr) & 0.08 & -0.95 (irr) & -1.34 (irr) & & [24] \\
\hline
\end{tabular}


Continuation of Table 2

\begin{tabular}{|c|c|c|c|c|c|c|c|c|c|c|c|}
\hline Compounds & System & Ref. & $E_{\text {Ox }}^{4}(\mathrm{~V})$ & $E_{\mathrm{Ox}}^{3}(\mathrm{~V})$ & $E_{\mathrm{Ox}}^{2}(\mathrm{~V})$ & $E_{\mathrm{Ox}}^{\mathrm{l}}(\mathrm{V})$ & $E_{\text {Red }}^{1}(\mathrm{~V})$ & $E_{\text {Red }}^{2}(\mathrm{~V})$ & $E_{\text {Red }}^{3}(\mathrm{~V})$ & $E_{\mathrm{Red}}^{4}(\mathrm{~V})$ & Ref. \\
\hline 50 & $\mathrm{DCM} / 0.1 \mathrm{M} \mathrm{TBAPF}{ }_{6}$ & $\mathrm{Fc} / \mathrm{Fc}^{+}$ & & & 1.11 (irr) & 0.07 & -0.93 (irr) & -1.32 (irr) & & & [24] \\
\hline 51 & $\mathrm{DCM} / 0.1 \mathrm{M} \mathrm{TBAPF}{ }_{6}$ & $\mathrm{Fc} / \mathrm{Fc}^{+}$ & & & 1.12 (irr) & 0.11 & -0.94 (irr) & -1.34 (irr) & & & {$[13,24]$} \\
\hline 52 & $\mathrm{DCM} / 0.1 \mathrm{M} \mathrm{TBAPF}{ }_{6}$ & $\mathrm{Fc} / \mathrm{Fc}^{+}$ & & & 1.28 (irr) & 0.52 & -0.35 & -0.71 & -1.32 & -1.80 & {$[13]$} \\
\hline 53 & $\mathrm{DCM} / 0.1 \mathrm{M} \mathrm{TBAPF}_{6}$ & $\mathrm{Fc} / \mathrm{Fc}^{+}$ & & & 1.21 (irr) & 0.48 & -0.79 (irr) & -0.88 (irr) & $\begin{array}{c}-1.16 \\
\text { (irr) }\end{array}$ & $\begin{array}{c}-1.29 \\
\text { (irr) }\end{array}$ & {$[13]$} \\
\hline 54 & $\mathrm{DCM} / 0.1 \mathrm{M} \mathrm{TBAPF}{ }_{6}$ & $\mathrm{Fc} / \mathrm{Fc}^{+}$ & & 1.34 (irr) & 1.10 (irr) & 0.40 & -0.73 (irr) & -1.42 (irr) & $\begin{array}{c}-2.03 \\
\text { (irr) }\end{array}$ & $\begin{array}{c}-2.23 \\
\text { (irr) }\end{array}$ & {$[13]$} \\
\hline 55 & $\mathrm{DCM} / 0.05 \mathrm{M}$ TBAF & $\mathrm{Fc} / \mathrm{Fc}^{+}$ & & 0.54 & 0.16 & 0.07 & -1.19 (irr) & -1.91 (irr) & & & {$[17]$} \\
\hline 56 & DCM / 0.1M TBAPF 6 & $\mathrm{Fc} / \mathrm{Fc}^{+}$ & & & 1.06 (irr) & 0.06 & -1.19 (irr) & -1.39 (irr) & & & [21] \\
\hline 57 & $\mathrm{DCM} / 0.1 \mathrm{M} \mathrm{TBAPF}_{6}$ & $\mathrm{Fc} / \mathrm{Fc}^{+}$ & & & 1.12 (irr) & 0.03 & -1.21 (irr) & -1.39 (irr) & & & {$[21]$} \\
\hline 58 & $\mathrm{DCM} / 0.1 \mathrm{M} \mathrm{TBAPF}{ }_{6}$ & $\mathrm{Fc} / \mathrm{Fc}^{+}$ & & & 1.07 (irr) & 0.06 & -1.14 (irr) & -1.25 (irr) & & & [21] \\
\hline 59 & $\mathrm{DCM} / 0.1 \mathrm{M} \mathrm{TBAPF}_{6}$ & $\mathrm{Fc} / \mathrm{Fc}^{+}$ & & & 1.12 (irr) & 0.10 & -1.24 (irr) & -1.28 (irr) & & & {$[21]$} \\
\hline 60 & DCM / 0.1M TBAP & SCE & & & & 0.56 & -0.67 & & & & {$[20]$} \\
\hline 61 & $\mathrm{DCM} / 0.1 \mathrm{M} \mathrm{TBAPF}_{6}$ & $\mathrm{Ag} / \mathrm{Ag}^{+}$ & & & 0.90 & 0.19 (irr) & -1.53 & & & & {$[12]$} \\
\hline 62 & $\mathrm{DCM} / 0.1 \mathrm{M} \mathrm{TBAPF}{ }_{6}$ & $\mathrm{Ag} / \mathrm{Ag}^{+}$ & & & 1.10 & 0.18 (irr) & -1.30 & & & & [12] \\
\hline 63 & DCM / 0.1M TBAP & $\mathrm{Fc} / \mathrm{Fc}^{+}$ & & & 0.60 (irr) & -0.13 & -1.10 (irr) & & & & {$[7]$} \\
\hline 64 & DCM / 0.1M TBAP & $\mathrm{Fc} / \mathrm{Fc}^{+}$ & & & & 0.10 & -1.10 & & & & {$[7]$} \\
\hline 65 & DCM / 0.1M TBAP & $\mathrm{Fc} / \mathrm{Fc}^{+}$ & & & 0.39 & 0.06 & -1.32 & & & & [7] \\
\hline 66 & $\mathrm{DCM} / 0.1 \mathrm{M}$ TBAP & $\mathrm{Fc} / \mathrm{Fc}^{+}$ & & & 0.80 (irr) & 0.12 & -0.96 (irr) & & & & {$[7]$} \\
\hline 67 & $\mathrm{DCM} / 0.1 \mathrm{M}$ TBAP & $\mathrm{Fc} / \mathrm{Fc}^{+}$ & & & 0.08 & -0.10 & -1.00 (irr) & & & & [7] \\
\hline 68 & DCM / 0.1M TBAP & $\mathrm{Fc} / \mathrm{Fc}^{+}$ & & & 0.15 & 0.09 & -0.96 & & & & [7] \\
\hline 73 & $\mathrm{BN} / 0.1 \mathrm{M}$ TBAP & $\mathrm{Fc} / \mathrm{Fc}^{+}$ & & & 0.68 & 0.02 & -0.80 & -1.07 & & & [23] \\
\hline 74 & $\mathrm{BN} / 0.1 \mathrm{M}$ TBAP & $\mathrm{Fc} / \mathrm{Fc}^{+}$ & & & 0.65 & 0.05 & -0.81 & -1.07 & & & {$[23]$} \\
\hline 75 & DCB / 0.1M TBAP & $\mathrm{Fc} / \mathrm{Fc}^{+}$ & & 0.58 & 0.27 & -0.03 & -1.72 & -1.88 & & & [19] \\
\hline 76 & AN/0.1M TBAP & $\mathrm{Fc} / \mathrm{Fc}^{+}$ & & & 0.820 & 0.528 & & & & & [37] \\
\hline 77 & AN/0.1M TBAP & $\mathrm{Fc} / \mathrm{Fc}^{+}$ & & & 0.805 & 0.536 & & & & & [37] \\
\hline 78 & AN/0.1M TBAP & $\mathrm{Fc} / \mathrm{Fc}^{+}$ & & & 0.796 & 0.496 & & & & & [37] \\
\hline 79 & AN/0.1M TBAP & $\mathrm{Fc} / \mathrm{Fc}^{+}$ & & & 1.051 & 0.503 & & & & & [37] \\
\hline 80 & AN/0.1M TBAP & $\mathrm{Fc} / \mathrm{Fc}^{+}$ & & & 1.163 & 0.504 & & & & & {$[37]$} \\
\hline 81 & AN/0.1M TBAP & $\mathrm{Fc} / \mathrm{Fc}^{+}$ & & & 1.166 & 0.575 & & & & & [37] \\
\hline
\end{tabular}
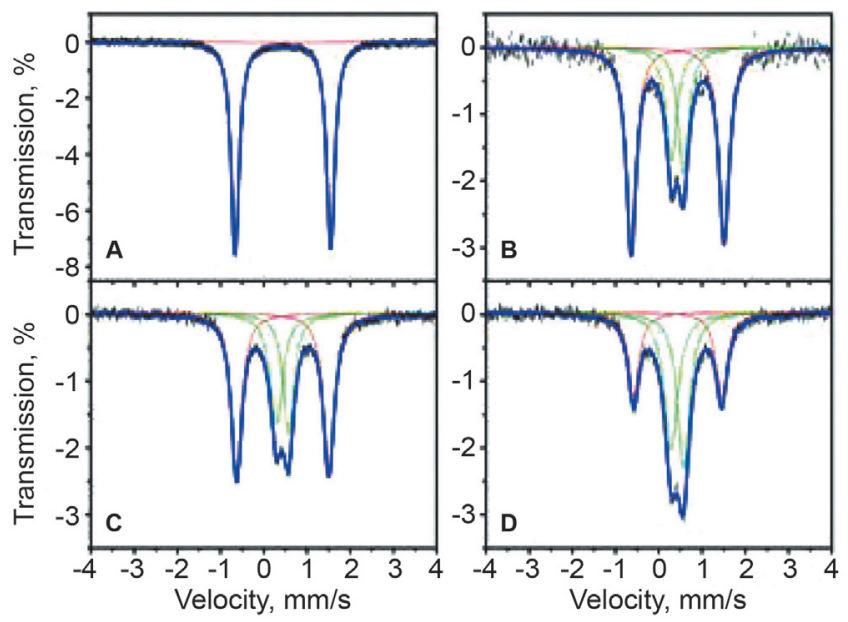

Figure 21. Mossbauer spectra of $8(\mathrm{~A}),[\mathbf{8}]^{+}(\mathrm{B}),[\mathbf{8}]^{2+}(\mathrm{C})$, and $[8]^{3+}(\mathrm{D})$. Reproduced with a permission from the American Chemical Society reference ${ }^{[6]}$. fragments are connected to the chromophore directly or via $-\mathrm{CH}=\mathrm{CH}-$ linking groups, the value of the first oxidation potential can be influenced to some extent by the electronic structure of the chromophore $\pi$-systems as they have substantial contributions in the HOMOs, which are delocalized over ferrocene fragments and chromophore cores.

Since reduction of ferrocene is expected to be outside of the electrochemical window in these experiments, all reduction processes observed for the ferrocene-containing BODIPYs and their analogues can be assigned to the reduction of $\pi$-system of the chromophore unit. In case of the diferrocenyl-containing BODIPY 14, ${ }^{[25]}$ spectroelectrochemical experiments supported such an assignment, as all changes associated with reduction of $\mathbf{1 4}$ to [14] $]^{-}$can be attributed to the presence of an additional electron at a BODIPY-centered MO. In general, the first reduction potential should correlate with the energy of the LUMO, which is a chromophorecentered MO with a large contribution from the meso-carbon or meso-nitrogen atom. Thus, either substitution of the 
meso-carbon atom with a more electronegative nitrogen (moving from BODIPY to aza-BODIPY) or replacement of the meso-C-H or meso-C-Aryl bonds with a meso-C-EW (EW=electron-withdrawing) fragment should result in a reduction of the energy of the LUMO and thus shift the first reduction potential in these systems to more positive values. Indeed, the first reduction potentials for aza-BODIPYs are shifted to more positive values compared to the corresponding BODIPY compounds. Similarly, the first reduction potential in diferrocene-containing BODIPY $15^{[9]}$ with meso$\mathrm{C}-\mathrm{CN}$ group is $360 \mathrm{mV}$ more positive compared to the first reduction potential observed for BODIPY analogue $\mathbf{1 3}^{[16]}$ with a meso-C-H fragment.

\section{Conclusions}

In this mini-review, we have summarized the general trends in photophysical and redox properties as well as electronic structures of ferrocenyl-containing BODIPYs, azaBODIPYs, BOPHYs, and transition-metal (aza)dipyrromethenes. This field continues to grow, and with the understanding of the factors that control spectroscopic and redox properties, chromophore-ferrocene conjugates with specific attributes can now be synthesized.

Acknowledgements. A Generous support by the NSF CHE1464711 grant, Minnesota Supercomputing Institute, University of Manitoba, and Canada WestGrid supercomputing facility to VNN is greatly appreciated.

\section{References}

1. Vecchi A., Galloni P., Floris B., Dudkin S.V., Nemykin V.N. Coord. Chem. Rev. 2015, 291, 95-171.

2. Vecchi A., Galloni P., Floris B., Nemykin V.N. J. Porphyrins Phthalocyanines 2013, 17, 165-196.

3. Ito O. Photoinduced Electron Transfer between Fullerenes and Electron-Donors through Molecular Bridges. In: Handbook of Carbon Nano Materials. Vol. 2 (D'Souza F., Kadish K.M., Eds.), 2011. pp. 441-477.

4. Dammer, S.J., Solntsev P.V., Sabin J.R., Nemykin V.N. Inorg. Chem. 2013, 52, 9496-9510.

5. Solntsev P.V., Spurgin K.L., Sabin J.R., Heikal A.A., Nemykin V.N. Inorg. Chem. 2012, 51, 6537-6547.

6. Zatsikha Y.V., Holstrom C.D., Chanawanno K., Osinski A.J., Ziegler C.J., Nemykin V.N. Inorg. Chem. 2017, 56, 991-1000.

7. Zatsikha Y.V., Didukh N.O., Blesener T., Kayser M.P., Kovtun Y.P., Blank D.A., Nemykin V.N. Eur. J. Inorg. Chem. 2017, 318-324.

8. Sharma R., Maragani R., Misra R. J. Organomet. Chem. 2016, 825-826, 8-14.

9. Didukh N.O., Zatsikha Y.V., Rohde G.T., Blesener T.S., Yakubovskyi V.P., Kovtun Y.P., Nemykin V.N. Chem. Commun. 2016, 52, 11563-11566.

10. Balsukuri N., Mori S., Gupta I. J. Porphyrins Phthalocyanines 2016, 20, 719-729.

11. Kaur N., Kaur P., Singh K. Sens. Actuators, B 2016, 229, 499505.

12. Wu X., Wu W., Cui X., Zhao J., Wu M. J. Mater. Chem., C 2016, 4, 2843-2853.
13. Dhokale B., Jadhav T., Mobin S.M., Misra R. Dalton Trans. 2016, 45, 1476-1483.

14. Jiang X.-J., Lau J.T.F., Wang Q., Ng D.K.P., Lo P.-C. Chem. Eur. J. 2016, 22, 8273-8281.

15. Shi W.-J., Lo P.-C., Zhao S., Wong R.C.H., Wang Q., Fong W.P., Ng D.K.P. Dalton Trans. 2016, 45, 17798-17806.

16. Zatsikha Y.V., Maligaspe E., Purchel A.A., Didukh N.O., Wang Y., Kovtun Y.P., Blank D.A., Nemykin V.N. Inorg. Chem. 2015, 54, 7915-7928.

17. Maligaspe E., Pundsack T.J., Albert L.M., Zatsikha Y.V., Solntsev P.V., Blank D.A., Nemykin V.N. Inorg. Chem. 2015, 54, 4167-4174.

18. Rhoda H.M., Chanawanno K., King A.J., Zatsikha Y.V., Ziegler C.J., Nemykin V.N. Chem. Eur. J. 2015, 21, 18043-18046.

19. Lim G.N., Maligaspe E., Zandler M.E., D'Souza F. Chem. Eur. J. 2014, 20, 17089-17099.

20. Ganapathi E., Madhu S., Ravikanth M. Tetrahedron 2014, 70, 664-671.

21. Misra R., Dhokale B., Jadhav T., Mobin S.M. Organometallics 2014, 33, 1867-1877.

22. Ziegler C.J., Chanawanno K., Hasheminsasab A., Zatsikha Y.V., Maligaspe E., Nemykin V.N. Inorg. Chem. 2014, 53, 4751-4755.

23. Bandi V., El-Khouly M.E., Ohkubo K., Nesterov V.N., Zandler M.E., Fukuzumi S., D’Souza F. J. Phys. Chem. C 2014, 118, 2321-2332.

24. Misra R., Dhokale B., Jadhav T., Mobin S.M. Dalton Trans. 2013, 42, 13658-13666.

25. Galangau O., Fabre-Francke I., Munteanu S., Dumas-Verdes C., Clavier G., Meallet-Renault R., Pansu R.B., Hartl F., Miomandre F. Electrochim. Acta 2013, 87, 809-815.

26. Dhokale B., Gautam P., Mobin S.M., Misra R. Dalton Trans. 2013, 42, 1512-1518.

27. Liu J.-Y., El-Khouly M.E., Fukuzumi S., Ng D.K.P. ChemPhysChem 2012, 13, 2030-2036.

28. Chen S., Chen W., Shi W., Ma H. Chem. Eur. J. 2012, 18, $925-$ 930.

29. Khan T.K., Pissurlenkar R.R.S., Shaikh M.S., Ravikanth M. J. Organomet. Chem. 2012, 697, 65-73.

30. Gautam P., Dhokale B., Mobin S.M., Misra R. RSC Adv. 2012, 2, 12105-12107.

31. Ziessel R., Bura T., Olivier J.-H. Synlett 2010, 2304-2310.

32. Yin X., Li Y., Zhu Y., Jing X., Li Y., Zhu D. Dalton Trans. 2010, 39, 9929-9935.

33. Rao M.R., Kumar K.V.P., Ravikanth M. J. Organomet. Chem. 2010, 695, 863-869.

34. Yin X., Li Y., Li Y., Zhu Y., Tang X., Zheng H., Zhu D. Tetrahedron 2009, 65, 8373-8377.

35. Zatsikha Y.V., Nemykin V.N. unpublished results.

36. Yadav M., Kumar P., Singh A.K., Ribas J., Pandey D.S. Dalton Trans. 2009, 9929-9934.

37. Gupta R.K., Pandey R., Singh R., Srivastava N., Maiti B., Saha S., Li P., Xu Q., Pandey D.S. Inorg. Chem. 2012, 51, 8916-8930.

38. Singh S.K., Kumar V., Drew M.G.B., Singh N. Inorg. Chem. Commun. 2013, 37, 151-154.

39. Jiang X.-D., Li S., Guan J., Fang T., Liu X., Xiao L.-J. Curr Org. Chem. 2016, 20, 1736-1744.

40. Zhao J., Xu K., Yang W., Wang Z., Zhong F. Chem. Soc. Rev. 2015, 44, 8904-8939.

41. Kowada T., Maeda H., Kikuchi K. Chem. Soc. Rev. 2015, 44, 4953-4972.

42. Singh S.P., Gayathri T. Eur. J. Org. Chem. 2014, 4689-4707.

43. Nemykin V.N., Hadt R.G. Inorg. Chem. 2006, 45, 8297-8307.

44. Nemykin V.N., Dudkin S.V., Fathi-Rasekh M., Spaeth A.D., Rhoda H.M., Belosludov R.V., Barybin M.V. Inorg. Chem. 2015, 54, 10711-10724. 